\title{
UMA SOMBRA DE DÚVIDA: REFLEXIVIDADE E FECHAMENTO EPISTÊMICO $^{1,2}$
}

Paulo Faria (UFRGS) ${ }^{3}$

\author{
paulo.faria@ufrgs.br
}

À memória luminosa de Balthazar Barbosa Filho

Resumo: $\mathrm{O}$ artigo examina as relações entre os princípios de Reflexividade e de Fechamento Epistêmico, com vistas a determinar se a rejeição do primeiro, usualmente requerida pelas análises externalistas do conceito de conhe-

\footnotetext{
${ }^{1}$ Recebido: 03.09.2010/Aprovado em 08.11.2010/Publicado on-line: 08/12/2010.

${ }^{2}$ Este artigo é o resultado da revisão de um texto preparado e enviado para distribuição prévia entre os participantes de um seminário que, a convite de Luiz Carlos Pereira, ministrei no Departamento de Filosofia da PUC-RIO em 13 de junho de 2003. Ao decidir-me a publicá-lo sete anos depois (sete anos no curso dos quais meus interesses e prioridades intelectuais tomaram, para minha própria surpresa, um rumo bem diverso do que anunciava este escrito), observei a "máxima de mutilação mínima", deixando para uma ocasião futura seja o desenvolvimento, seja a reconsideração, de pontos que permaneceram insuficientemente articulados no texto original. Afora correções tópicas de gramática ou estilo; da supressão ou acréscimo, em benefício da clareza, de algumas passagens, especialmente nas páginas conclusivas; e de uma atualização mínima da bibliografia, limitei-me a corrigir um par de erros manifestos - o mais embaraçoso dos quais me fora apontado punctualmente por Luiz Carlos Pereira por ocasião do seminário na PUC-RIO. A ele e aos demais participantes daquele seminário, em particular a Oswaldo Chateaubriand, quero deixar registrada minha gratidão pela discussão que tivemos, e por mais de uma observação crítica de que guardei vívida memória; que tive o tempo todo presente, agora, ao revisar este escrito; e a que, todavia, sigo despreparado para fazer inteira justiça. A quitação dessas dívidas que o tempo decorrido não fez prescrever permanece na minha agenda, mesmo se tudo que posso fazer, nas atuais circunstâncias, é renovar a moratória. Quando eu empreendia a revisão do texto original, uma conversa com Alfredo Storck despertou-me a atenção para a falta de clareza em minha compreensão do único ponto a respeito do qual, nestas páginas, é mencionada a epistemologia de Aristóteles; e uma indicação de Raphael Zillig permitiu-me tirar uma dúvida importante sobre a interpretação de Platão que aqui apresento. Agradeço ao primeiro a advertência, e ao segundo a orientação, com a ressalva usual, que se aplica igualmente aos críticos da versão original deste escrito, de que aquilo que nele ainda precise ser endireitado é, como todo outro erro, confusão ou obscuridade que este escrito possa conter, de minha inteira e exclusiva responsabilidade. Assinalo, por fim, que tanto a redação como a revisão deste escrito foram beneficiadas pelo apoio de bolsas de produtividade em pesquisa concedidas pelo CNPq (processos PQ 304648/2002-7 e 305758/2009-8, respectivamente).

${ }^{3}$ Paulo Faria é Professor-adjunto da Faculdade de Filosofia da Universidade Federal do Rio Grande do Sul, Porto Alegre, Brasil e Pesquisador 1B do CNPq.
} 
cimento, deve acarretar, igualmente, o abandono do segundo. A resposta negativa obtida a essa pergunta suscita a hipótese de que aparentes contraexemplos ao Princípio de Fechamento Epistêmico sejam artefatos das condições muito peculiares em que, no curso de certo tipo de investigação epistemológica, devem ser introduzidas as suposições que caracterizam o recurso metodológico às assim-chamadas "dúvidas" céticas.

Palavras-chave: Ceticismo, Princípios Epistêmicos, Fechamento Epistêmico, Racionalidade, Reflexividade, Paradoxo de Moore.

As notas que seguem são o memorando de uma tentativa de investigar as relações entre dois postulados que a tradição epistemológica tomou como constitutivos do conceito de conhecimento - os princípios de Reflexividade e de Fechamento Epistêmico - com vistas a determinar se a rejeição do primeiro deve acarretar, igualmente, o abandono do segundo. Em particular, interessa-me examinar a hipótese de que contraexemplos ao Princípio de Fechamento Epistêmico sejam artefatos das condições muito peculiares em que, no âmbito do inquérito epistemológico sobre a confiabilidade dos processos ordinários de aquisição de crenças (trate-se de percepção, memória, testemunho ou inferência), devem ser introduzidas as suposições que caracterizam o recurso metodológico às assim chamadas (impropriamente, se eu tiver razão) "dúvidas" céticas. Se essa conjetura estiver correta, é possível neutralizar satisfatoriamente uma importante fonte de resistência à alternativa oferecida pelo externalismo epistemológico à compreensão do conhecimento como crença verdadeira justificada ${ }^{4}$. Como um benefício adi-

\footnotetext{
${ }^{4}$ Por certo, nessa definição canônica do conhecimento (cuja introdução é usualmente atribuída como se verá, com alguma licença interpretativa - a Platão no Teeteto), tudo depende do que se deva entender por 'justificação'. Se essa palavra não visa mais que as credenciais (qualquer que seja sua natureza) que qualificam a crença verdadeira do sujeito ao título de conhecimento, nenhum
} 
cional, é possível conferir um sentido determinado à intuição, que concorda com o irrefletido "dogmatismo" do senso comum e da prática científica normal (no sentido de Kuhn) de que a "dúvida" cética é, como escreveu memoravelmente Peirce, 'dúvida de papel' - uma sombra de dúvi$\mathrm{da}^{5}$.

A tarefa é, portanto, promover uma avaliação das relações entre esses dois postulados, o Princípio de Reflexividade:

(PR) Se S sabe que p, então S sabe que sabe que $p .^{6}$

e o Princípio de Fechamento Epistêmico:

(PFE) Se S sabe que p, sabe que p implica q, e infere q de p, então $S$ sabe que q. ${ }^{7}$

dos críticos históricos do internalismo epistemológico, de Ramsey a Goldman ou Dretske, teria objeção a empregar aquela definição canônica. A questão disputada - o pomo da discórdia na controvérsia entre internalismo e externalismo epistemológicos - reside, como é amplamente reconhecido, em saber se essa justificação deve estar acessivel ao sujeito do conhecimento, na forma de razões que estaria apto a oferecer em resposta a uma impugnação de suas credenciais.

${ }^{5} \mathrm{O}$ defensor esclarecido do senso comum (o 'Critical Common-sensist', rótulo que Peirce (1965, p. 361-362 [\$ 5.514]) aplica a sua própria filosofia) 'tem uma elevada estima pela dúvida. Pode-se mesmo dizer que ele tem uma sacra fames por ela. Só que sua fome não é saciada por dúvidas de papel: ele exige o metal pesado e nobre, ou então a crença'. O repúdio do método cartesiano da dúvida é articulado na primeira secção ('The Spirit of Cartesianism') do célebre artigo 'Some Consequences of Four Incapacities', publicado no Journal of Speculative Philosophy 2 (1868), pp. 140-157), e reimpresso nos Collected Papers (1965, Vol. V, pp. 156-189).

${ }^{6}$ Esse princípio também é conhecido como a 'tese KK', em razão da notação usual, introduzida por Hintikka em Knowledge and Belief (1962), para os operadores epistêmicos: 'A validade da tese', observa Risto Hilpinen (1992, p. 234), 'é sensível a oscilações no significado de 'saber'; pensou-se com frequência que ela caracteriza um conceito forte de conhecimento (p. ex. o conhecimento baseado em razões conclusivas), ou o conhecimento ativo por oposição ao implícito'. Do juízo que se deva fazer sobre a suficiência de uma epistemologia restrita à consideração do que Hilpinen chama 'um conceito forte de conhecimento' dependerá, evidentemente, a admissibilidade da suposição, expressa em PR, de que a reflexividade é constitutiva do conhecimento; em outras palavras, de que a verdade de 'S sabe que sabe que p' é condição necessária da verdade de 'S sabe que $p^{\prime}$.

${ }^{7} \mathrm{Ou}$, para empregar uma formulação corrente, o conhecimento é 'fechado pela implicação conhecida'. Um conjunto é dito 'fechado por' (closed under) uma operação quando todo resultado de 
A admissibilidade de cada um desses dois postulados pode, e deve, ser examinada separadamente. Mas eu estarei interessado em examinar, em primeiro lugar, sua independência. Especificamente, interessa-me examinar a possibilidade de que a rejeição do Princípio de Reflexividade devesse acarretar, igualmente, a do Princípio de Fechamento Epistêmico.

É certo que, do estrito ponto de vista histórico, o abandono de ambos os princípios caracterizou algumas das mais influentes versões históricas do externalismo epistemológico, notadamente as que foram propostas por Fred Dretske e Robert Nozick, no bojo da maré de reações suscitadas pelo "problema de Gettier". Mas a motivação do abandono permaneceu por muito tempo (especialmente no caso mais problemático do segundo, o Princípio de Fechamento Epistêmico) insuficientemente articulada, envolvendo, seguidamente, pouco mais que o apelo às "intuições" evocadas por cada participante do debate acerca da cogência de uma variedade de alegados contraexemplos ${ }^{8}$. Apenas em algumas raras publicações mais recentes ${ }^{9}$ foram dados os primeiros

uma aplicação dessa operação a um elemento do conjunto é, ele próprio, um elemento do conjunto; assim, por exemplo, o conjunto dos números naturais é fechado pela operação sucessor de: todo resultado da aplicação dessa operação a um número natural é, também, um número natural. (A metáfora espacial do fechamento tem, como se vê, uma aplicação quase literal: uma operação "fecha" um conjunto quando, não importa quão longe possamos ir em sua aplicação, nunca "saímos" do conjunto.) Analogamente, tudo que sabemos ser implicado por algo que sabemos é, também - uma vez "aplicada a operação": vale dizer, destacado o consequente do condicional que sabemos ser verdadeiro -, algo que, ipso facto, sabemos.

${ }^{8}$ Assim, por exemplo, a taxonomia dos operadores epistêmicos esboçada por Dretske (1970), no artigo que constitui o locus classicus da rejeição do Princípio de Fechamento Epistêmico, não passa de uma regimentação terminológica do contraste entre as diferentes classes de exemplos, imaginativamente descritos - e, por certo, intuitivamente diferentes, em algum sentido que fica por ser esclarecido -, de que se ocupa o ensaio.

${ }^{9} \mathrm{Na}$ primeira versão deste escrito (cf. nota 2) eu mencionava Peter Klein (1996), Mark Heller (1999), Anthony Brueckner (2000) e Duncan Pritchard (2000). O aggiomamento requerido para dar conta do avanço da discussão na última década converteria esta nota em um novo artigo. Impossibilitado (e, também, despreparado) para proceder a essa revisão bibliográfica, limito-me a 
passos rumo a uma avaliação sistemática do que esteve em jogo na discussão - extremamente interessante e, ao mesmo tempo, notavelmente inconclusiva - dos últimos quarenta $\operatorname{anos}^{10}$. Uma consequência desse estado de coisas é que nenhuma investigação sistemática foi ainda empreendida, até onde sei, sobre as relações entre Reflexividade e Fechamento Epistêmico. As notas que seguem pretendem contribuir para cobrir essa lacuna.

A meu ver, o princípio de uma reconstrução racional do debate epistemológico contemporâneo, que prepare o terreno para uma avaliação adequada daqueles dois princípios epistêmicos, deve ser buscado na genealogia comum às variedades do internalismo e do externalismo epistemológicos de nossos dias. Uma alusão à interrogação platônica - inaugurada no Mênon, e em outros diálogos socráticos do período intermediário, e levada à culminação no Teeteto sobre as condições do conhecimento bastará para indicar o que eu tenho em vista ao falar em "genealogia comum" 11.

\footnotetext{
chamar a atenção do leitor para a discussão do fechamento epistêmico no excelente livro de Duncan Pritchard, Epistemic Luck (2005); para o debate entre Fred Dretske e John Hawthorne no volume editado por Matthias Steup e Ernest Sosa, Contemporary Debates in Epistemology (2005); e para o artigo de Claudio de Almeida, 'Closure, Defeasibility and Conclusive Reasons' (2007). O acerto de contas com este último, em particular, requereria mais um artigo que ainda não estou preparado para escrever. Minhas dificuldades são agravadas por um novo trabalho, ainda em preparação, de Claudio de Almeida, apresentado em versões preliminares no Primeiro Congresso Latinoamericano de Filosofía Analítica, em Mérida, Yucatán (México), em 14 de abril de 2010, e no Terceiro Colóquio Brasileiro de Epistemologia Contemporânea, na PUCRS, em Porto Alegre, em 9 de junho de 2010.

${ }^{10}$ Cf., além dos trabalhos citados nas duas notas precedentes, Gail C. Stine (1971); Irving Thalberg (1976); Gail C. Stine (1976); Palle Yourgrau (1983); Colin McGinn (1984); Anthony L. Brueckner (1985); Radu J. Bogdan (1985); Roy A. Sorensen (1988); Jonathan Vogel (1990); e Richard Feldman (1995). O primeiro esforço de articulação teórica da rejeição do fechamento epistêmico foi empreendido, até onde eu sei, por Robert Nozick (1981). Cf., para uma apresentação da gama de reações suscitadas pela tentativa de Nozick, os ensaios reunidos em Steven Luper-Foy (1987).

${ }^{11}$ Para uma apresentação contemporânea do debate entre internalismo e externalismo - que teria sido beneficiada, como tanta coisa na epistemologia de nossos dias, por algum sentido de perspectiva histórica - cf. Dretske (2000, p. 80-93).
} 
A primeira etapa da investigação platônica do conhecimento (o estabelecimento da distinção entre crer e saber) não é especialmente relevante para os propósitos da presente exposição: essencialmente, Platão argumenta em favor da "Lei de Parmênides", o princípio

(LP) 'S sabe que p' implica 'p'.'

As dificuldades, das quais não é exagero dizer que constituem o repertório inteiro da epistemologia como disciplina filosófica, emergem com a demonstração de que uma crença verdadeira não é ainda conhecimento se pelo menos uma condição adicional não estiver satisfeita.

No Mênon, Platão caracterizava essa condição adicional em termos da ideia de estabilidade: tal é o sentido da metáfora que compara as (meras) crenças a 'esculturas de Dédalo' que é preciso plantar no chão para evitar que se evadam $^{13}$. As cadeias que devem assegurar esse cativeiro da crença são, já àquela altura, identificadas por Platão com a força das razões ${ }^{14}$. No estágio final do inquérito platônico

\footnotetext{
${ }^{12} \mathrm{Ou}$, como dizia Austin: 'Se sei, não posso estar errado'. O nome 'Lei de Parmênides' foi sugerido por Hintikka (1962, p. 22).

${ }^{13}$ Mênon, 97e-98a. Em 'Le dialogue platonicien comme forme de pensée ironique', Stefania Nonvel Pieri escreve: 'De resto, se remontamos às origens, de epistẹme a epístamai e a ephístémi, o que reúne as diferentes acepç̃es desses termos é a estabilidade, o "deter-se".' (2001, p. 32). Devo ressalvar que não tenho autoridade para atestar a exatidão filológica dessa afirmação. $\mathrm{O}$ dicionário etimológico de Pierre Chantrainne, em todo caso, não a abona, mesmo se não a desautoriza por

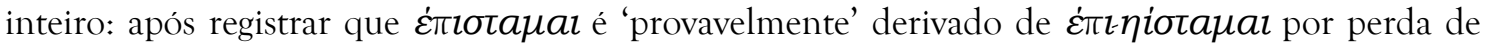
aspiração e contração, Chantrainne (1990, p. 360) observa que essa segunda palavra 'distingue-se

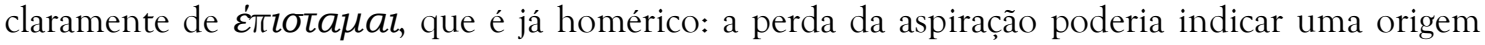
jônica que não surpreenderia. O sentido original é alguma coisa como "por-se acima de"; a palavra foi aplicada de início a atividades práticas'.

14 'aitias גoyıo $\mu \omega$ ' (Mênon, 98a). Maura Iglésias, seguindo nisso outros tradutores, opta pela versão literal: 'um cálculo de causa' (cf. Platão, 2001, p. 103). Em seu inestimável artigo 'Anamnesis in the Meno', Vlastos (1965, p. 143-167, reimpresso em Day, 1994, p. 69) adverte contra essa opção: “Causa' por aitía aqui (Jowett, Meridier, Bluck) é enganador, pois o uso filosófico moderno reserva o termo para relações que instanciam leis da natureza, nunca para relações puramente lógicas. Assim, falar das premissas de um silogismo como a altia da conclusão (Aristóteles, Segundos
} 
(aquele que corresponde à conclusão, se algo pode ser chamado a conclusão, do Teeteto) conhecimento é crença verdadeira 'acompanhada de razão' - e a tarefa remanescente é elucidar o que deva ser essa 'razão' (logos), que precisa acompanhar a crença verdadeira para que ela se caracterize como conhecimento.

Mas talvez devêssemos guardar-nos de apresentar o resultado obtido por Platão como equivalente à caracterização internalista do conhecimento como crença verdadeira justificada. Pois isso equivaleria a dar ao requisito de estabilidade uma interpretação que, se é certo que captura muito do que Platão tem a dizer, nas difíceis páginas conclusivas do Teeteto (201d-210d), sobre esse logos que deve acompanhar a crença verdadeira, de modo algum pareceria ser a história inteira. Em particular, essa interpretação deixa sem explicar a função que o apelo a uma forma de apreensão acusativa, não-proposicional, dos constituintes últimos da Realidade (o "sonho" de que fala Sócrates) (Cf. Teeteto, 201d-206d) cumpre na elucidação do logos introduzido em $201 \mathrm{~d}^{15}$.

Analíticos 71b22) seria o mais grosseiro dos erros categoriais se o termo de Aristóteles significasse o que entendemos por 'causa'.' (A própria Jane Day opta por 'reasoning out the explanation', p. 69.)

${ }^{15}$ A obscuridade, assim como o fascínio, da parte final do diálogo provêm, em boa medida, da ambiguidade dessa noção de logos: o sonho atomista evocado por Sócrates - segundo o qual, dos elementos primeiros, não é possível 'dar razão' - é, essencialmente, um recurso heurístico para tornar manifesta essa ambiguidade, explicitamente discutida em 206c e ss. O primeiro passo (por certo que é apenas o primeiro, mas decisivo) para a compreensão do Sonho consiste em reconhecer sua relação com o paradoxo do juízo falso, discutido em 187a-200d do Teeteto, e posteriormente retomado - e, finalmente, resolvido - no Sofista. Nos dois casos, estão em jogo as relações entre conhecimento proposicional ('S sabe que p') e conhecimento acusativo ('S conhece x'): a tentação de caracterizar o segundo como condição necessária do primeiro, que se faz sentir inequivocamente nessa parte final do Teeteto, deve muito de seu apelo à promessa que encerra de uma solução unitária para o problema metafísico da falsidade (ou do não-ser) e para o problema epistemológico da estabilidade do conhecimento. A força hipnótica desse apelo é atestada pela influência que exerceu, na filosofia contemporânea, a tese russelliana do caráter derivado do conhecimento proposicional (knowledge by description) em relação ao conhecimento acusativo (knowledge by acquaintance). Comentando a apresentação do Sonho (Teeteto 201e-202b, citado in extenso na tradução alemã de 
A consideração dos argumentos que motivaram a introdução do requisito de estabilidade lança luz sobre essa dificuldade - e fornece, como tentarei mostrar a seguir, o fio condutor para a genealogia da controvérsia entre internalismo e externalismo na epistemologia de nossos dias.

De fato, aquele requisito era, desde sua introdução no Mênon, um requisito de não acidentalidade da crença verdadeira (como deixa claro, no Teeteto 200d-201c, o exemplo do Júri: cf. Burnyeat \& Barnes, 1980, p. 173-206). A ideia básica é, simplesmente, que, quando $S$ sabe que $p$, não é mera sorte epistêmica de $\mathrm{S}$ ter a crença que p: antes, é porque $p$ é verdadeiro que $\mathrm{S}$ crê que $p$.

Mas, até aí, nenhuma ideia definida de justificação foi ainda introduzida. Tudo que o exame das condições do conhecimento (as condições de verdade de 'S sabe que p') trouxe à tona foram essas três cláusulas: se $\mathrm{S}$ sabe que $p$, então
(1) S crê que $p$
(2) $p$
(3) (1) porque (2)

\footnotetext{
Preisendanz), Wittgenstein (1989a, p. 264) - em geral, um leitor muito mais agudo de outros filósofos do que sugere seu professado descaso pela possibilidade de que 'alguém mais já tivesse pensado' o que pensara - observa: 'Esses elementos primeiros eram, também, os individuals de Russell e meus 'objetos' (Tractatus Logico-Philosophicus)'. A afinidade apontada por Wittgenstein nessa passagem é investigada por John McDowell em 'Identity Mistakes: Plato and the Logical Atomists' (1998, p. 157-170)' Sobre o “sonho” de Sócrates, cf. Gilbert Ryle (1990, p. 21-46) e os comentários de John McDowell (1973, p. 231-257) e Myles Burnyeat (1990, p. 134-234).

${ }^{16}$ Em seu comentário ao Teeteto, John McDowell (1973, p. 228) escreve, a propósito do exemplo do júri persuadido, pela arte retórica de um orador, de uma versão verdadeira de fatos que não testemunharam pessoalmente (201a4-c7): 'Pode parecer excessivamente restritivo sugerir que apenas testemunhas oculares poderiam conhecer a verdade acerca de um roubo: talvez devamos admitir a possibilidade de conhecimento por-ouvir-dizer (knowledge by hearsay). Mas é claro que isso não afeta o argumento contra a tese de que conhecimento é juízo verdadeiro. [...] $\mathrm{O}$ argumento
} 
Mas essa formulação (a que eu chamarei, daqui em diante, a Análise Mínima do conceito de conhecimento) é neutra entre pelo menos duas interpretações da conjunção subordinativa adverbial 'porque'. Na primeira delas, a nãoacidentalidade consiste em um nexo racional (portanto, normativo) entre crença e verdade: e o que (3) está dizendo é que $S$ dispõe de razões suficientes para crer que $p$ : razões que está apto a apresentar em resposta a um pedido de justificação. Na segunda, a não-acidentalidade consiste em um nexo causal (não-normativo), entre crença e verdade: e o que (3) está dizendo é que a verdade de $p$ é um antecedente causal da crença que (1) atribui a $S^{17}$.

Para não deixar dúvida: eu não estou sugerindo que uma teoria causal do conhecimento da espécie das que, em nossa época, foram propostas por filósofos como Alvin Goldman (1967) ou David Armstrong (1973) - teria sido, para Platão ou algum outro filósofo antigo, uma opção disponível $^{18}$. Mas a possibilidade de que uma hesitação sobre a natureza da necessidade a ser atribuída ao nexo entre crença e verdade não tivesse sido alheia às reticências de Platão sobre esse ponto difícil tem um interesse intrínseco, independente de seu disputável valor como conjetura exegéti-

\footnotetext{
dessa passagem suscita o seguinte pensamento: a razão por que um juízo, ou crença, verdadeiro, da espécie descrita aqui, não é um caso de conhecimento é que se chega a ele não porque os fatos são como são, mas por causa da determinação do advogado, que era independente dos fatos. Isso sugere que o próximo passo deveria ser a elaboração da idéia de que o que é requerido, além da verdade, para que um juízo, ou crença, seja um caso de conhecimento é que ele seja formado porque os fatos são tais que o tornam verdadeiro'.

${ }^{17}$ Pace Vlastos, e sem por isso endossar a tradução criticada do Mênon (cf. nota 14) - cujo maior defeito, para o que aqui importa, reside justamente em remover, optando pela menos plausível das alternativas, a ambiguidade que estou assinalando (é certo que preservando a ideia de 'cálculo', גoyı ${ }^{\prime}$ 's: cf. sobre essa palavra, Vlastos, 1965, p. 96).

${ }^{18}$ Especificamente, essa sugestão envolveria o risco de anacronismo: de estar retroprojetando a compreensão moderna da causalidade (herdada, em suas linhas gerais, da Revolução Científica do século XVII) na interpretação do pensamento antigo.
} 
$\mathrm{ca}^{19}$. Pois o que a consideração da ambiguidade apontada no parágrafo precedente torna manifesto é o caráter nãocompulsório da interpretação internalista do requisito de estabilidade.

'Externalismo epistemológico' é, bem entendido, o nome genérico de uma família de doutrinas, de que as teorias causais do conhecimento são apenas um ramo, mais que de alguma teoria epistemológica particular. Para meus propósitos presentes, é suficiente atermo-nos ao traço comum que as distingue: a rejeição da ideia de que a satisfação da condição (3) da Análise Mínima (o requisito de estabilidade de Platão) deva ser, ela própria, epistemicamente acessivel ao sujeito.

$\bigcirc$ argumento básico em favor dessa rejeição compartilha, com os argumentos do externalismo semântico (cf. FARIA, 2001, 2006, 2009, 2010), a prioridade conferida ao ponto de vista do atribuinte (a "perspectiva da terceira pessoa”) na investigação da semântica das atitudes proposicionais ${ }^{20}$. A necessidade desse deslocamento de perspectiva é a

\footnotetext{
${ }^{19}$ Aristóteles, em troca, impôs explicitamente uma condição "causal" ao conhecimento (cf. Segundos Analiticos, I 2, 71b9-12); mas essa era a condição de que as premissas de que é inferida uma conclusão fossem, para a conclusão constituir um caso de conhecimento demonstrativo, causas (em algum sentido aristotélico de 'causa', cf. as notas 14 e 18) da conclusão. Em outras palavras, a "teoria causal do conhecimento" de Aristóteles é, também, uma teoria estritamente internalista: conhecimento, exceção feita ao conhecimento dos primeiros princípios, é crença verdadeira demonstrada - e nisso Aristóteles estabeleceu o padrão para a tradição epistemológica subsequente. Quanto ao conhecimento dos primeiros princípios, é certo que ele deve ser imediato (e, assim, independente das razões-que-são-causas de que é derivado o conhecimento demonstrativo); mas a condição de imediatidade é, justamente, uma condição de acessibilidade epistêmica (cf. a seguir); e, assim, igualmente uma condição internalista - e nisso, novamente, Aristóteles estabeleceu o padrão para seus sucessores.

20 'Num como noutro caso, a especificação do conteúdo proposicional envolve considerações sobre aspectos do contexto (do ambiente natural e social, das práticas da comunidade de usuários da linguagem) em que está envolvido o atribuído, que podem não ser epistemicamente acessíveis ao próprio atribuído. Em outras palavras, os princípios de atribuição não têm sua aplicação inibida por condições de 'compreensão incompleta' como aquelas em que se encontram os usuários de designadores rígidos no argumento básico da Nova Teoria da Referência, ou os protagonistas do expe-
} 
conclusão comum de uma família de argumentos filosóficos cujo membro mais celebrado e influente, na filosofia analítica do século XX, talvez tenha sido o assim-chamado "argumento da linguagem privada" de Wittgenstein. Um corolário igualmente comum dessa família de argumentos é que as condições de autoatribuição de atitudes proposicionais são parasitárias daquelas em que outros são corretamente reconhecidos como sujeitos de atitudes proposicionais ${ }^{21}$. Para o caso específico do conceito de conhecimento, esses argumentos impõem o reconhecimento da possibilidade de que as condições do conhecimento (a aquisição de uma crença verdadeira por um processo que exclui a sorte epistêmica, satisfazendo, assim, o requisito de estabilidade de Platão) estejam satisfeitas ainda que o sujeito a quem - corretamente, em tais circunstâncias - se deva atribuir conhecimento possa não reconhecer que estão: e, assim, esteja na situação de saber sem saber que sabe ${ }^{22}$.

A primeira consequência da rejeição da exigência internalista de acessibilidade é, assim, o abandono do Princípio de Reflexividade: se alguma versão do externalismo episte-

\footnotetext{
rimento imaginário de Putnam; mas isso equivale a dizer que esses princípios são incompatíveis com o Postulado de Transparência do Conteúdo Proposicional.' (Faria, 2001, p. 119).

${ }^{21}$ Talvez o mais antigo precursor dessa família de argumentos seja a célebre secção sobre 'Independência e Dependência da Consciência de Si' (a "dialética do senhor e do escravo") na Fenomenologia do Espírito de Hegel. A dedução das categorias 'temáticas' da intencionalidade representacional a partir de categorias que poderíamos chamar "operatórias" (as categorias da intencionalidade não-representacional) na Primeira Divisão de Ser e Tempo de Heidegger tem a mesma consequência anti-individualista - ainda que o preço a pagar pela dependência essencial do Dasein seja a 'queda' (Verfall) na 'inautenticidade' (Uneigentlichkeit): cf. a discussão do 'estar-aícom' (Mitdasein) no cap. IV (Heidegger, 1993, p. 113-130). Sob a dupla influência de Hegel e Heidegger, Sartre parece haver contribuído com mais um membro para essa família de argumentos em L'être et le néant: cf. Gregory McCullouch (1994, p. 106-111). Uma versão mais recente do argumento básico, manifestamente mais próxima, quando mais não seja no léxico, de Wittgenstein que de Heidegger ou Sartre, é apresentada por Donald Davidson em 'The Second Person' (2001, p. 107-121).

${ }^{22}$ Essa assimetria entre a primeira e a terceira pessoas terá consequências decisivas, como se verá, para a avaliação da "falácia da dedução válida" de que adiante se trata.
} 
mológico é correta, 'S sabe que p' não implica 'S sabe que sabe que p': o conhecimento não é essencialmente reflexivo, contrariamente ao que tendeu a supor boa parte da tradição epistemológica. Isso, bem entendido, não equivale a abandonar o ideal regulativo de reflexividade: o princípio de responsabilidade epistêmica que impõe, a um sujeito racional, o ônus de justificar suas crenças ${ }^{23}$. O que o externalismo deve rejeitar é a "ilusão transcendental" consistente em tomar esse princípio regulativo por um princípio constitutivo - em outras palavras, em tomar o consequente de PR pelo enunciado de uma condição necessária do conhecimento $^{24}$.

$\mathrm{O}$ abandono de PR tem consequências imediatas para as relações entre epistemologia e ceticismo. Pois, se é possível saber sem saber que se sabe, o exame das condições do conhecimento é inteiramente dissociável da compulsão de "refutar o cético", provando que aquelas condições podem ser satisfeitas, projeto que dominou (com resultados tão altissonantes quanto, invariavelmente, fracassados) a tradição internalista moderna ${ }^{25}$.

\footnotetext{
${ }^{23}$ A ideia subjacente é que tratar alguém como um sujeito racional importa necessariamente em tratá-lo como capaz de justificar a escolha de afirmar uma proposição ao invés de negá-la, ou suspender o juízo.

${ }^{24}$ Uma consequência dessa importante ressalva é que os casos de conhecimento desacompanhado de razões serão, para um externalismo esclarecido, a exceção e não a regra. Cf., a esse respeito, as pertinentes observaçoes de Robert Brandom em 'Knowledge and the Social Articulation of the Space of Reasons' (1995, p. 895-908), e em 'Insights and Blindspots of Reliabilism' (2000, p. 97122). Na alternativa sugerida, a rejeição de $P R$ vai de par com a adoção do que poderíamos chamar o Princípio Deontológico de Reflexividade (PDR): 'Se S sabe que p, então $S$ deve saber que sabe que p'. A reflexividade, nessa alternativa, será entendida como uma virtude epistêmica no sentido delineado, em particular, por Ernest Sosa, em Apt Belief and Reflective Knowledge (2007, 2009).

${ }^{25}$ Três breves observações: (i) Os externalistas são usualmente enfáticos ao anunciar essa gratificante consequencia. Cf., por exemplo, Fred Dretske (1970, p. 34-35), Robert Nozick (1981, p. 197-247). (ii) Para uma avaliação negativa dessa alegação, cf. Barry Stroud (2000, p. 139-154). (iii) Discutir essa avaliação negativa é tarefa para outro artigo, cujo ponto de partida seria a distinção entre duas variedades de sorte epistêmica introduzida por Mylan Engel (1992, p. 59-75), e retomada, e substancialmente refinada, por Duncan Pritchard em vários escritos, notadamente em
} 
Por certo, se, convencido por um argumento cético, eu deixo de crer no que, antes, pretendia saber, deixo também, eo ipso, de sabê-lo. Suponhamos, porém, que tudo que o argumento consegue lograr é (como costuma ser o caso com os argumentos céticos) que eu deixe, ao menos interinamente, de crer que sei que $p$ é verdadeiro, sem por isso deixar - por mais que tente, agarrando-me ao argumento cético de crer que $p$ é verdadeiro: em outras palavras, sem que isso importe em efetiva suspensão do juízo ${ }^{26}$. Nesse caso, o veredicto externalista é que meu conhecimento subsiste ile$\mathrm{so}^{27}$.

Como isso é possível? A intuição mais fundamental das análises externalistas é que a crença de $\mathrm{S}$ na verdade de $p$ será conhecimento caso tenha sido formada em condições tais que, se $p$ fosse falso, $\mathrm{S}$ não teria essa crença ${ }^{28}$. As teorias causais do conhecimento são apenas a articulação mais tosca da intuição subjacente a esse condicional ${ }^{29}$. Na análise confiabilista introduzida por Ramsey em 1929, redescoberta e articulada por Goldman em 'Discrimination and Percep-

\footnotetext{
Epistemic Luck (2005).

${ }^{26}$ Poderíamos chamar a esse resultado embaraçoso do exercício da capacidade racional de autoavaliação crítica 'A Enrascada de Hume'. É essa a situação em que emerge o simulacro de violação de PFE de que adiante se trata.

${ }^{27}$ A apresentação desse resultado por Nozick em Philosophical Explanations (1981, pp. 211-227 e 245-247) é particularmente clara e cuidadosa.

${ }^{28}$ Essa é condição conhecida na literatura recente como 'sensitividade'. Essa condição não é suficiente para assegurar a satisfação da cláusula (3) da Análise Mínima (a exclusão da sorte epistêmica). Falta ainda uma condição de 'segurança' (safety): S acreditaria que $p$ é verdadeiro em toda situação relevante (em todo mundo possível suficientemente próximo do mundo atual) em que $p$ fosse verdadeiro. Mas o conjunto que contém (1) S crê que p, (2) p, (3) Se p fosse falso, $S$ não creria que p e (4) Se p fosse verdadeiro, $S$ creria que p ainda não é um conjunto de condições suficientes do conhecimento: de fato, nada (é aí que vou chegar em seguida) poderia sê-lo se o externalismo for verdadeiro.

${ }^{29}$ Entre as muitas coisas que essa articulação deixa sem explicar estão o conhecimento matemático e o conhecimento empírico de proposições envolvendo generalidade lógica: em que sentido, por exemplo, o fato que $2+3=5$ poderia ser um antecedente causal da crença que $2+3=5$ ? Cf. a propósito, Sven Bernecker \& Fred Dretske (2000, p. 4)
} 
tual Knowledge' (1976), e adotada desde então pela grande maioria dos externalistas, conhecimento é crença verdadeira obtida através de um processo confiável ${ }^{30}$.

O ponto decisivo aqui é que o processo de formação de crenças de S seja confiável, não que S saiba que é ${ }^{31}$. É nisso que essas análises são, propriamente, externalistas: é da "perspectiva da terceira pessoa" - da perspectiva do atribuinte em uma atribuição de conhecimento - que elas suscitam e respondem à pergunta sobre as condições do conhecimento.

Mas, e essa é uma segunda e surpreendente consequência, geralmente despercebida, de qualquer análise externalista, nenhum conjunto de condições necessárias e suficientes pode, tampouco, ser especificado para a satisfação da terceira cláusula na Análise Mínima do conhecimento. Trate-se de causalidade, confiabilidade ou alguma outra condição menos específica como o "rastreamento" (tracking) de Nozick, o essencial acerca dessa condição "externa" de estabilidade é que sua formulação envolve o uso ineliminável de condicionais subjuntivos (cf., no parágrafo precedente, a cláusula: 'Se $p$ fosse falso, $S$ não teria essa crença') $)^{32}$. Mas

\footnotetext{
${ }^{30}$ Cf. Frank P. Ramsey (1965, p. 258-259); Alvin I. Goldman (1976, p. 771-791). Retrospectivamente, podemos reconhecer elementos de confiabilismo em mais de uma abordagem clássica dos problemas epistemológicos - por exemplo, na dissolução (fundada na prova da existência de um Deus Veraz) da hipótese 'hipérbólica' do Sonho na Sexta Meditação cartesiana; ou na defesa dos 'primeiros princípios das verdades contingentes' no sexto dos Essays on the Intellectual Powers of Man, de Reid. Esses e outros exemplos ilustram um princípio enunciado, numa passagem célebre, por Jorge Luís Borges (1976, p. 109): 'O fato é que cada escritor cria seus precursores. Seu trabalho modifica nossa concepção do passado, como modificará o futuro'.

${ }^{31}$ Analogamente, na análise causal anteriormente proposta por Goldman, o que era requerido era que $p$ fosse um antecedente causal da crença de $S$, não que $S$ soubesse que era.

${ }^{32} \mathrm{Na}$ análise de Nozick (1981), 'S sabe que p' é verdadeiro se, e somente se, (1) S crê que $p$, (2) p; (3) Se $p$ fosse falso, $S$ não creria que $p$, (4) Se $p$ fosse verdadeiro, $S$ creria que $p$. As cláusulas (3) e (4) são condicionais subjuntivos: elas descrevem "mundos possíveis" em que $p$ seria, respectivamente, falso e verdadeiro. Se as condições (3) e (4) estão, cumulativamente, satisfeitas, a crença de S, no jargão de Nozick, "rastreia" (tracks) o fato p. O rastreamento de Nozick é, assim, como o ne-
} 
condicionais subjuntivos, diversamente dos condicionais indicativos (da assim-chamada 'implicação material'), são refratários ao reforço do antecedente (strenghtening): na lógica das funções de verdade (o cálculo proposicional clássico), 'Se A e B, então C' é verdadeiro sempre que 'Se A, então C' seja verdadeiro; mas a verdade do condicional subjuntivo 'Se este fósforo fosse riscado, acenderia' é perfeitamente compatível com a falsidade de 'Se este fósforo fosse riscado e estivesse molhado, acenderia' 33 .

E é assim que chegamos (na "ordem das razões, posto que não no "contexto da descoberta" histórico) à ideia de alternativas relevantes. Fred Dretske é, até onde eu sei, o introdutor da expressão, e o primeiro filósofo a ter investigado com alguma atenção as consequências, para a análise de 'S sabe que p', do ponto que acabo de assinalar ${ }^{34}$. A ideia básica, porém, pode ser encontrada - como notou Barry Stroud (1984, p. 44, nota 4) - em J. L. Austin ${ }^{35}$ :

Se nos certificamos que é um pintassilgo, e um pintassilgo real, e depois ele faz algo extravagante (explode, cita a Sra. Woolf, ou o que seja), não dizemos que estávamos enganados ao dizer que era um pintassilgo real: não sabemos o que dizer. Faltam-nos, literalmente, as palavras. ${ }^{36}$

\footnotetext{
xo causal nas teorias de Goldman e Armstrong, uma condição de covariância entre crença e verdade. Cf. Robert Nozick (1981, p. 172-178), e a análise de Roberto Horácio Sá Pereira (2001, p. 205-221).

${ }^{33}$ A literatura sobre condicionais subjuntivos é imensa; cf., para algumas discussões clássicas, Roderick Chisholm (1946, p. 289-307); Nelson Goodman (1947, p. 113-128), , reimpresso como Capítulo 1 de Fact, Fiction, and Forecast (1983, p. 3-27); David Lewis (1973); Elizabeth Anscombe (1981, p. 196-207); Frank Jackson (1987); David Sanford (1989); e os artigos reunidos em Frank Jackson (1991).

${ }^{34}$ Mesmo se não foi nesses termos que ele o apresentou: cf. Dretske 1970, 1971, 2000.

${ }^{35}$ E, também, nas Investigações Filosóficas de Wittgenstein.

${ }^{36}$ Austin, 1979, p. 88. Em 'The Meaning of a Word' (1939, cf. Austin 1979, p. 67), Austin apresenta um exemplo semelhante: 'Suponhamos que eu vivo em paz e harmonia com um gato durante quatro anos: e então ele profere uma oração filípica. Perguntamo-nos, talvez, 'É um gato real?
} 
Por certo, se o objeto que estivemos observando vier a explodir, não era um pintassilgo - e alegar que, mesmo assim, estávamos justificados em afirmar 'Isso é um pintassilgo' não equivale a alegar que sabíamos o que, nesse caso, não poderíamos saber. É certo que, nesse e em outros casos anômalos, eu não poderia saber que estava diante de um pintassilgo. Mas isso não se deve a que eu não dispusesse de justificação adequada. Simplesmente não posso saber que $p$ se p é falso (pela condição (2) da Análise Mínima, LP). Se minha justificação ("-Como você sabe?" "-Pela cor do bico”) é adequada, tudo que ainda é preciso para que minha crença seja conhecimento é que a pressuposição de que o suposto pássaro não vai explodir (ou citar Virginia Woolf) seja verdadeira: não preciso, além disso, saber que é verdadeira $^{37}$.

Mas, chegados a esse ponto, pareceria que estamos compelidos a rejeitar o Princípio de Fechamento Epistêmico. Pois a lição do externalismo pareceria ser que o conhecimento não poderia estar fechado pela implicação conhecida

\footnotetext{
ou não é um gato real?' 'Ou é, ou não é, mas não podemos decidir com certeza.' Mas, de fato, não é assim: nem 'É um gato real' nem 'Não é um gato real' ajustam-se semanticamente aos fatos: cada uma dessas expressões é apropriada para outras situações que não esta: você não poderia dizer 'É um gato real' de algo que profere filípicas, mas também não poderia dizer 'Não é um gato real' de algo que se comportou como isso por quatro anos a fio' . A lição que Austin extraía desse exemplo era que 'a linguagem ordinária entra em colapso em casos extraordinários'. (idem, p. 68). O repúdio do postulado de determinação completa (da ideia de que a aplicação de um conceito é determinada por um conjunto de condições necessárias e suficientes) é uma tese comum a Austin e a Wittgenstein. A poltrona que desaparece, reaparece, torna a desaparecer, etc., das Investigações Filosóficas (§ 80), cumpre função análoga, no contexto da crítica de Wittgenstein ao postulado da determinação do significado, à dos exemplos de Austin: 'O que devemos dizer agora? Você tem regras prontas para casos assim - que digam se ainda de deve chamar 'poltrona' uma coisa dessas?' (Loc. cit.). Warren Goldfarb compara esses exemplos de Austin e de Wittgenstein em 'Wittgenstein and the Fixity of Meaning' (1997) - a melhor introdução que eu conheço à filosofia das Investigações Filosóficas.

${ }^{37}$ E, assim, tampouco preciso saber que não estou sonhando ou sendo enganado por um Enganador: é suficiente que isso não esteja, de fato, acontecendo.
} 
porque pelo menos uma de suas condições (que a crença do sujeito tenha sido formada através de um processo confiável de formação de crenças: nos termos de Nozick, por um método que "rastreia" a verdade) não o está.

Se confiabilidade é uma propriedade disposicional, a ser explicada (como toda propriedade disposicional) fazendo uso ineliminável de condicionais subjuntivos, então a condição (3) da Análise Mínima (a condição de estabilidade de Platão) não poderia, prima facie, estar fechada pela implicação conhecida. Eu posso, por exemplo, ser um discriminador confiável (um "rastreador") de casas em estilo colonial português, saber que, se algo é uma casa (em estilo colonial português), não é uma fachada pintada para uma produção cinematográfica - e mesmo assim, não ser capaz de discriminar (de "rastrear") o fato de estar percorrendo os estúdios de uma grande produção cinematográfica, caso isso esteja acontecendo ${ }^{38}$.

Essa consequência lançaria luz sobre uma propriedade intrigante da "dúvida" cética, que não escapou ao reconhecimento dos fundadores da filosofia moderna, a Descartes e Hume em particular. Refiro-me a sua instabilidade e evanescência, à notória impossibilidade em que nos encontramos de preservá-la fora do contexto muito peculiar dos experimentos imaginários a que devemos recorrer para introduzi-la: esses recitais de vitimização metafísica com o auxílio dos quais - devidamente assegurados de que 'não se trata aqui de agir, mas de meditar e de conhecer ${ }^{\prime 39}$ - ocu-

\footnotetext{
${ }^{38}$ Cf. Alvin I. Goldman (1976, pp. 771-791), onde é apresentado o célebre exemplo de 'Phony Barn Country', introduzido originalmente por Carl Ginet, e anos mais tarde modificado, e convertido em uma objeção usualmente tida como devastadora à análise de Nozick, por Kripke; mas veja-se, a este respeito, o contra-ataque de Fred Adams e Murray Clarke (2004, p. 18-20).

${ }^{39}$ Descartes, 1976-1982, v. VII, p. 22; v. IX-1, p. 17, edição doravante referida pela sigla AT.
} 
pamo-nos em fazer de conta que duvidamos de coisas das quais (como todo mundo também sabe) 'ninguém em seu são juízo jamais duvidou' (DESCARTES, AT, v. VII, p. 1516; v. IX-1, p. 12).

Assim, no final da Primeira Meditação cartesiana, a ficção do Gênio Maligno é convocada em auxílio à decisão de 'enganar-me a mim mesmo, fingindo que todos esses pensamentos são falsos e imaginários' (AT, v. VII, p. 22; v. IX, p. 17) ${ }^{40}$. A necessidade desse exercício de autoengano é uma decorrência, explicitamente assinalada por Descartes, da instabilidade dos resultados da aplicação do método da dúvida. Essa instabilidade, Descartes tematiza-a invocando o risco de uma recaída em suas 'antigas opiniões'. Com efeito, 'não basta ter feito tais considerações, é preciso ainda que cuide de lembrar-me delas' (AT, v. VII, p. 22; v. IX, p. 17) ${ }^{41}$.

A mesma dificuldade é assinalada por Hume nessa passagem célebre do Tratado da Natureza Humana que descreve o retorno à filosofia depois de um abandono temporário aos cuidados e encantos mundanos:

Eu janto, jogo uma partida de gamão, converso, divirto-me com meus amigos; e quando, depois de três ou quatro horas de entretenimento, quiser retornar a essas especulações, elas me parecem tão

\footnotetext{
${ }^{40}$ Essa ficção não deve ser confundida com a suposição, introduzida em um estágio anterior da "ordem da razões" (àquele que corresponde à ficção do Deus Enganador), de que todas as "minhas" crenças sejam falsas.

${ }^{41}$ Em outras palavras - e apelando para a metáfora judiciária que Hume e Kant empregarão ao descreverem esses procedimentos de avaliação radical da possibilidade e limites do conhecimento humano como um todo em termos da instituição de um "tribunal da Razão" - o Gênio Maligno não participa, como o Deus Enganador com o qual o confundem alguns intérpretes menos cuidadosos, da instrução do inquérito: sua tarefa é, em troca, a preservação (e, caso necessário, a restauração) dos autos após o encerramento da instrução. O caráter dessa ficção metodológica, sua serventia heurística para manter viva a 'lembrança' do experimento cético contra a pressão constante do esquecimento, são explicitamente discutidos nas Quintas Respostas, onde Descartes compara o recurso ao Gênio Maligno à técnica de endireitar uma vara torta torcendo-a em sentido oposto: cf. Descartes (AT, v. VII, p. 340-350).
} 
frias, artificiais e ridículas que já não tenho ânimo de prosseguir com elas. $^{42}$

Mas essas meditações, tanto no caso de Descartes como no de Hume, parecem propor uma explicação psicológica (a força do hábito e do preconceito, a compulsão natural ao assentimento) para a instabilidade do ceticismo epistemológico $^{43}$. A sugestão alternativa de que as propriedades lógicas dos condicionais subjuntivos poderiam fornecer a chave para a explicação desse fenômeno - em outras palavras, que essa era uma instabilidade lógica e não empírica - é, sem dúvida, uma das grandes promessas do externalismo epistemológico. Mas não é exagero dizer que estamos ainda longe de poder considerá-la cumprida ${ }^{44}$. Em minha primeira tentativa de acertar contas com essa

\footnotetext{
${ }^{42}$ Hume, 1978, p. 269. O filósofo fala sinceramente: se não entendermos até que ponto todas as questões da filosofia chegam a parecer-lhe, a cada tanto, 'frias, artificiais e ridículas', tampouco entenderemos a seriedade de que essas questões se revestem para ele. Pois estaremos, neste caso, igualmente inclinados a subestimar a 'melancolia' e o 'desespero' - o sentimento de ter sido jogado na 'mais deplorável condição que se possa imaginar, cercado da mais profunda escuridão, e de todo privado do uso de quaisquer membros e faculdades' (Ibid.) - que são, para Hume, a recompensa de seus esforços filosóficos.

${ }^{43} \mathrm{Na}$ literatura epistemológica contemporânea, pertence inequivocamente a Thompson Clarke o mérito de haver chamado atenção para o fenômeno, em seu importante e influente ensaio 'The Legacy of Skepticism' (Clarke, 1972). O tema da instabilidade da dúvida cética percorre a discussão, inspirada em Clarke, do "problema do mundo exterior" na segunda parte de The Claim of Reason, de Stanley Cavell (1979). Está, também, no coração da controvérsia sobre a interpretação do ceticismo pirrônico que envolveu Michael Frede, Myles Burnyeat e Jonathan Barnes: os textos pertinentes estão agora reunidos no volume editado por Burnyeat e Barnes The Original Sceptics: a Controversy (1997).

${ }^{44}$ Em Unnatural Doubts: Epistemological Realism and the Basis of Scepticism, Michael Williams apresenta também a sugestão, que ele chama 'algo especulativa', de que 'os filósofos que negaram o fechamento podem ter estado respondendo a algo real, que eu chamo "a instabilidade do conhecimento".' (WILLIAMS, 1996, p. xxi). O que Williams chama a 'instabilidade do conhecimento' é, de fato, sua própria versão (fundada em uma análise contextualista do conceito de conhecimento) do problema de Descartes e Hume - isto é, da instabilidade da dúvida epistemológica. Embora eu não possa acompanhar o diagnóstico proposto por Williams para essa 'instabilidade' - e, de modo geral, deva rejeitar a estratégia de dissolução do ceticismo pela via do que Williams chama 'diagnose teórica' (essencialmente, o programa de desocultor pressupostos teóricos opcionais do ceticismo que, uma vez tornados explícitos, estaríamos livres para descartar) - a hipótese que estou tentando explorar deveria contribuir para a atribuição de um sentido preciso àquela sugestão.
} 
promessa, atribuí a Robert Nozick a formulação original da tese de que as propriedades lógicas do "operador epistêmico" 'S sabe que...' continham a chave para a elucidação da instabilidade da dúvida cética. Nozick, com efeito, extrai de sua análise do conceito de conhecimento ${ }^{45}$ (com suas duas condições subjuntivas) o corolário de que a dúvida cética só pode "durar" enquanto dura a consideração explícita de uma possibilidade que (como é o caso das ficções cartesianas do Sonho, do Deus Enganador e do Gênio Maligno) não poderíamos "rastrear" (track). Afinal, se eu estivesse sonhando, alucinando ou sendo enganado por um Enganador, tomaria por verídicas minhas percepções presentes, ainda que elas não o fossem - o que viola a primeira das duas condições subjuntivas da análise do conhecimento proposta em Philosophical Explanations: a condição que hoje chamamos 'de sensitividade'. E se eu fosse persuadido por um cético (ou, ainda, uma vez por um gênio maligno) de que minhas percepções verídicas eram ilusórias, não as tomaria por verídicas - o que viola a segunda das duas condições subjuntivas da análise de Nozick: a condição que hoje chamamos 'de segurança'.

Para Nozick, em suma, os argumentos céticos mostram (corretamente) que não sabemos que certas possibilidades não estão realizadas: se elas estivessem realizadas, mesmo assim acreditaríamos que não estavam. Mas esses argumentos não mostram que não sabemos outras coisas (inclusive coisas que implicam que aquelas possibilidades não estão realizadas), pois essas outras coisas são possibilidades que "rastreamos" - e, assim, candidatos admissíveis ao título de

\footnotetext{
${ }^{45}$ Análise que, todavia, pretendia justamente oferecer um conjunto de condições necessárias e suficientes do conhecimento.
} 
conhecimento. Mas esse resultado aplica-se igualmente ao cético filosófico: pois, como todo mundo, também ele rastreia essas outras possibilidades. Assim, "não é de surpreender que, quando se ocupa delas, de sua relação com tais fatos, o cético descubra ser difícil lembrar ou manter sua opinião de que não conhece esses fatos.' (NOZICK, 1981, p. 211). Para reavivar seu ceticismo, ele precisaria 'voltar sua atenção', outra vez, para as consequências que (como todo mundo) não rastreia de tais fatos ${ }^{46}$; 'caso contrário, não é de surpreender que se veja forçado a confessar o pecado da credulidade'. (idem, ibidem).

O fato de não estarem compelidas a rejeitar o problema da instabilidade para o limbo da "psicologia da pesquisa", ou do "contexto da descoberta", é, ostensivamente, uma vantagem prima facie das abordagens externalistas do ceticismo sobre toda epistemologia que nos imponha a tarefa desesperada de "refutar o cético" - uma vantagem suficientemente importante para justificar o exame atento da possibilidade de que as considerações que motivam a rejeição do Princípio de Reflexividade pudessem importar, igualmente, na rejeição do Princípio do Fechamento Epistêmico.

A espinhosa dificuldade remanescente é a de saber se essa vantagem poderia compensar o custo do abandono daquele princípio - especialmente se for o caso que (como estou inclinado a pensar), mais do que as propriedades dos "operadores epistêmicos", é a função que cumpre o reconhecimento de relações lógicas (e, especificamente, da consequência lógica) na expansão do conjunto das crenças justificadas de um sujeito racional que está em jogo ${ }^{47}$. A i-

\footnotetext{
${ }^{46}$ Por exemplo: 'Não estou sonhando' ou 'Não estou sendo enganado'.

${ }^{47}$ Essa objeção às epistemologias que (como as de Dretske ou Nozick) abraçam a rejeição do PFE
} 
deia é apanhada, lapidarmente, em uma observação informal de Saul Kripke, em seu seminário do outono de 1996 em Princeton: exceções ao Princípio de Fechamento Epistêmico, caso haja alguma, é bom que sejam muito raras; do contrário, seria sempre legítimo rejeitar a conclusão indesejada de um argumento objetando: 'Essa é a bem-conhecida falácia de fazer uma dedução válida'!

Aqui é preciso andar com cuidado. Por certo, se eu posso saber sem saber que sei, meu conhecimento de que $p$ implica $q$ pareceria fadado a permanecer logicamente inerte nos casos em que eu sei que $p$, mas não sei que o sei: por exemplo, porque (quem sabe, depois de estudar os argumentos céticos) não creio que o processo de formação de minha crença na verdade de $p$ seja confiável. Mas posso encontrarme nessa situação?

O final do Primeiro Livro do Tratado da Natureza Humana, na medida em que seja (como eu penso que é) uma descrição acurada da fenomenologia da dúvida cética, parece ilustrar exemplarmente essa possibilidade. $\mathrm{O}$ sujeito das agonias epistemológicas descritas por Hume pode muito bem saber muitas coisas (tendo obtido suas crenças por processos confiáveis envolvendo o uso adequado da percepção, da memória, do testemunho e da inferência); saber, com certeza, que suas crenças são incompatíveis com diversas suposições mais ou menos 'frias, artificiais e ridículas'; mas, tendo perdido a confiança nos processos a que deve a aquisição dessas crenças, está logicamente paralisado, incapaz

foi-me apresentada, pela primeira vez, por Balthazar Barbosa Filho, em memorável discussão travada no dia 26 de setembro de 1994 - o dia em que deixei de acreditar em Dretske e Nozick. O impasse de que este texto é uma espécie de memorando é o saldo de mais de uma tentativa que, desde então, empreendi de acertar contas com essa objeção. 
de destacar as conclusões implicadas por suas premissas.

Mas esse não poderia ser um contraexemplo ao PFE, justamente porque o sujeito que, nessas circunstâncias, sabe ser verdadeiro que $p$ implica $q$ não destaca o consequente do condicional: não infere $q$ das duas premissas que implicam essa conclusão. Do mesmo modo, não inferimos que o vistoso equino listrado que admiramos no jardim zoológico em um cercado assinalado 'ZEBRA (Equus Quagga)' não é uma mula habilmente disfarçada para parecer uma zebra (DRETSKE, 1970, p. 39); tampouco alguém infere, da observação de seu entorno, que não está imerso em um tanque em Alfa do Centauro (NOZICK, 1981, p. 205) embora, em todos esses casos, estejamos aptos (e, em condições normais, dispostos) a dar assentimento tanto ao condicional como a seu antecedente.

Por certo, há pelo menos uma diferença prima facie entre a situação descrita por Hume e os exemplos apresentados por Dretske e Nozick como casos paradigmáticos de violação do PFE. O filósofo entregue ao que Hume descreve como 'profunda e intensa reflexão' (1978, p. 218)' suspende (volens nolens) o juízo sobre o antecedente, e parece chegar a esse resultado por contraposição: 'Sei que $p$ implica q; não sei que q; logo, não sei que p' - em outras palavras, por aplicação estrita do PFE. Mas esse filósofo é o mesmo 'homem natural' cujo 'descuido e desatenção' benfazejos restituem-lhe, invariavelmente, todas as certezas abaladas pelo que não passou, e não passa nunca, de 'uma perplexidade e confusão momentâneas' (HUME, 2007, p. 116-117).

Nos exemplos de Dretske e Nozick, em troca, o 'descuido e desatenção' estendem-se ao próprio condicional cujo consequente acena, ominosamente, para um cenário cético. $\mathrm{O}$ 
visitante do zoológico de Dretske, como, antes dele, o identificador de pintassilgos de Austin (1979, p. 88), nem mesmo cogitam das possibilidades remotas (as alternativas irrelevantes) que ameaçariam sua pretensão de saber que animal estão observando. Nozick (algo mais nuançadamente, como se viu) contrasta, como Hume, as situações em que prevalecem o 'descuido e desatenção', e em que, descuidados e desatentos, não hesitamos em pensar coisas como 'Aqui está uma mão humana, e aqui está outra', com o esforço concentrado de atenção (a palavra é de Nozick) que é requerido para não perder de vista que o método pelo qual formamos crenças como aquela não "rastreia" a possibilidade de estarmos imersos em um tanque em Alfa do Centauro.

Mas, com isso, chegamos a um dilema: ou (1) estamos entregues à 'profunda e intensa reflexão', cujo desfecho é a suspensão do juízo, por modus tollens, sobre nossas crenças naturais (e, nesse caso, estamos empregando o PFE); ou (2) estamos usufruindo dos benefícios do 'descuido e desatenção', e não inferimos, por modus ponens, que sabemos que não estamos em um cenário cético (e tampouco violamos, por isso mesmo, o PFE). E, no entanto, esses eram os casos paradigmáticos de "contraexemplos" ao Princípio de $\mathrm{Fe}$ chamento Epistêmico! ${ }^{48}$

O que isso mostra? Que, para que o dogmatismo benigno com que negligenciamos as hipóteses céticas possa ser apresentado como uma violação do PFE, precisamos já estar operando em certo regime de duplicidade ou oscilação de registro, da espécie que, na filosofia de Hume, toma a forma

\footnotetext{
${ }^{48}$ Sobre as ambiguidades de escopo (de re / de dicto) que infectam boa parte dos restantes exemplos originais de Dretske, cf. o artigo clássico de Gail C. Stine (1971).
} 
de um conflito entre a Norma da Razão e a Norma da Natureza.

Essa me parece ser a intuição fundamental, e o núcleo aproveitável, do contextualismo epistemológico introduzido por Gail Stine (1976) e desenvolvido, desde então, por filósofos como Stewart Cohen, David Lewis ou Keith DeRo$\mathrm{se}^{49}$. Mas não precisamos abraçar o contextualismo para preservar aquela intuição fundamental: do que precisamos, em troca, é (como Peirce havia notado) da distinção entre duvidar e fazer de conta que se duvida.

Em The Varieties of Reference, Gareth Evans recorreu à teoria da ficção de Kendall Walton (1973, 1878, 1990), originariamente introduzida como uma contribuição à teoria estética, para elucidar o 'fenômeno mais sutil e complicado que a teoria da referência deve explicar - o uso conivente de termos singulares vazios' (Evans, 1982, p. 124). O programa ao qual o presente ensaio é uma introdução consiste em examinar as perspectivas de uma extensão das análises de Walton ao exame desse fenômeno sutil e evanescente, cuja afinidade com a ficção e a simulação é tão manifesta quanto recalcitrante à elucidação filosófica: a dúvida 'de papel' que distingue o uso (ou abuso) do ceticismo na filosofia moderna.

Eu não seria capaz de aprimorar a descrição que faz, do que chamei, linhas acima, 'duplicidade”, Myles Burnyeat:

Hoje em dia, se um filósofo encontra dificuldade em responder à pergunta filosófica "O que é o tempo?" ou "O tempo é real?", solicita uma bolsa de pesquisa para trabalhar no problema durante uma licença no ano que vem. Ele não supõe que a chegada do ano que vem está realmente em dúvida. Alternativamente, ele pode conceder

\footnotetext{
${ }^{49}$ A exposição mais persuasiva, a meu juízo, do programa contextualista encontra-se no artigo maravilhoso de Lewis (1996), reimpresso em Lewis (1999, p. 418-445).
} 
que qualquer perplexidade acerca da natureza do tempo, ou qualquer argumento para duvidar da realidade do tempo, é, de fato, uma perplexidade sobre, ou um argumento sobre, a verdade da proposição segundo a qual a licença do ano que vem vai chegar, mas mesmo assim alegar que isso é, por certo, uma preocupação estritamente teórica ou filosófica, não uma preocupação a ser levada em conta na vida quotidiana. De um modo ou de outro, ele insula seus juízos ordinários de primeira ordem dos efeitos de sua filosofia. (BURNYEAT, 1997, p. 92)

A estratégia mais promissora, a meu juízo, para elucidar esse 'insulamento' de que fala Burnyeat - mas aqui posso apenas, em conclusão, esboçá-la - parte da hipótese de que a melhor explicação filosófica de que dispomos dessa duplicidade (e, com ela, do caráter fingido, simulado, 'de papel', da "dúvida" cética) é a análise das relações entre 'asserção' (Behauptung) e 'suposição' (Annahme) que Wittgenstein articulou em oposição ostensiva a Frege ${ }^{50}$ e aplicou ao tratamento do Paradoxo de Moore. Se essa hipótese estiver correta, o Princípio do Fechamento Epistêmico e o Paradoxo de Moore ${ }^{51}$ são, de fato, duas faces de um mesmo pro-

\footnotetext{
${ }^{50} \mathrm{E}$, de fato, na contramão da quase toda a tradição filosófica moderna. As exceções (os precursores da crítica de Wittgenstein a Frege) são Espinosa e Kant - mas esse é mais um assunto para outra ocasião. (A quem interessar possa, em todo caso: os textos pertinentes estão em Espinosa, Ética II, 49, escólio; e Kant, Critica da Razão Pura, A 73-76 / B 98-101.)

${ }^{51}$ Cf. L. Wittgenstein (1989a, p. 513-517; 1989b, Vol. I, §§ 470-504, 700-708, 715-719, 750-753, 787, 812-824, 907, 972; Vol. II, §§ 169, 277-290, 302, 354, 416-420; e 1989c, Vol. I, Vorstudien zum Zweiten Teil der Philosophische Untersuchungen, §§ 82-88, 141-145, 416-428, 522-526; Vol. II, Das Innere und das Äußere, 1949-1952 p. 8-12). Discuti esses textos em meu ensaio 'Le guêpier de Moore' (Faria 2001), mas minha discussão era comprometida pela atribuição a Wittgenstein - e, o que é pior, pela aceitação - da análise "expressivista" de 'Creio que p' (para a qual o proferimento de uma frase dessa forma é, grosso modo, equivalente à 'asserção hesitante', como diz Wittgenstein, de 'p'). Hoje penso que (pace Peter Hacker, Joachim Schulte et alii) essa não é a análise de Wittgenstein; e também, o que é muito mais importante, que é uma análise falsa (pace Jane Heal, Arthur Collins et alii). Fui despertado de meu "sono dogmático" pela leitura do livro de Richard Moran, Authority and Estrangement: an Essay on Self-Knowledge (2001): cf., em particular, a breve mas penetrante seção 'Wittgenstein on Moore's Paradox' (idem, pp. 69-77). Embora a revisão da exegese de Wittgenstein seja o menos importante dos dois pontos sobre os quais mudei de opinião, faço questão de assinalar que, tal como compreendo agora a discussão por Wittgenstein do Paradoxo de Moore, estou longe de poder acompanhar o juízo de Claudio de Almeida (2009, p. 49),
} 
blema.

O postulado que orienta essa conjetura é que uma explicação satisfatória da incongruência das conjunções anômalas de Moore ('Creio que p, mas não-p', 'p, mas não creio que p') deve poder dar conta tanto do uso expressivo da construção 'Creio que p', para o qual inicialmente chamou atenção Wittgenstein (o uso em que 'Creio que está chovendo' expressa um juízo sobre o tempo que está fazendo), quanto de seu uso atributivo (o uso em que 'Creio que está chovendo' - como suas contrapartidas em outras pessoas e tempos verbais, ou no modo subjuntivo - atribui um juízo: nesse caso, ao próprio sujeito do proferimento).

Ora, se é certo que a análise "expressivista" reminiscente de algumas das observações de Wittgenstein (quase sempre lidas, transcritas ou parafraseadas sem qualquer cuidado de compreendê-las em seus contextos originais de ocorrência) acena para a perspectiva de explicar a incongruência das conjunções de Moore como um fenômeno lógico (mesmo se 'contradição' é, para não deixar qualquer dúvida, uma palavra absolutamente descabida em uma caracterização cuidadosa do fenômeno), essa alternativa paga o preço de deixar sem explicação a anomalia que, ostensivamente, continua a comprometer a inteligibilidade das conjunções de Moore mesmo em uma interpretação atributiva da construção 'Creio que p' - que era, a propósito, o problema em que o próprio Moore estava interessado.

Se as análises contemporâneas de inspiração "wittgensteiniana" negligenciam, desastrosamente, o uso atributivo

para quem 'é certo que nem Moore, nem Wittgenstein, estavam habilitados a compreender a extensão do problema'. A discussão da requintada análise do Paradoxo de Moore desenvolvida, ao longo da última década, por Claudio de Almeida, é a última tarefa cujo diferimento para outra ocasião devo aqui deixar consignado. Vejam-se, especialmente, Claudio de Almeida 2001 e 2007. 
que preocupava Moore, boa parte da literatura mais recente sobre o Paradoxo de Moore, em troca, parece incorporar a suposição de que, para o uso expressivo, a solução do problema seria trivial e, por isso mesmo, filosoficamente desinteressante. $O$ resultado assemelha-se a uma conversa de surdos, e alimenta a suspeita de que 'Paradoxo de Moore' chegou a ser a designação equívoca de pelo menos dois problemas filosóficos muito diferentes. Essa suspeita, vai-se ver, deve ser rejeitada, mas está claro que o sucesso de qualquer tentativa de integrar em uma explicação unitária a incongruência das conjunções de Moore em suas duas interpretações dependerá da explicação de que disponhamos da relação entre os usos expressivo e atributivo dos verbos intencionais.

Como assinalei, esse último foi, constantemente, o único que Moore teve em vista. Veja-se, como exemplo, o texto usualmente citado como o locus classicus da formulação do paradoxo:

[...] dizer algo como "Fui ao cinema na última quinta-feira, mas não creio que tenha ido", é dizer uma coisa perfeitamente absurda, embora o que é afirmado seja perfeitamente possível do ponto de vista lógico: é perfeitamente possível que você tenha ido ao cinema e mesmo assim não creia tê-lo feito. (MOORE, 1942, p. 543)

Essa passagem é de um ensaio publicado em 1942, mas o problema tem raízes bem mais antigas, remontando, de fato, a essa "revolta contra o idealismo" a que devemos o nascimento do que (hoje) chamamos 'filosofia analítica" ${ }^{152}$, e cujo documento inaugural foi o ensaio de Moore, 'The Nature of Judgment', publicado em 1899.

Nele, Moore empreendeu a crítica, a que em seguida vi-

52 "Foi no fim de 1898 que Moore e eu nos rebelamos contra Kant e Hegel” (Russell, 1959, p. 42). 
ria a associar-se Russell, aos fundamentos lógico-filosóficos das doutrinas metafísicas do idealismo. Moore identificava, na concepção do juízo como exercício de capacidades 'ativas' do espírito, sem cujo concurso nenhum objeto de experiência se poderia constituir, a raiz de um amálgama desastroso entre as condições da verdade de uma proposição e as condições do assentimento a essa proposição. A confusão entre essas duas ordens de condições, por sua vez, abria o caminho para a usurpação da Metafísica pela Epistemologia, que distinguiria a tradição idealista.

Em Principia Ethica (publicado em 1903, mesmo ano da publicação dos Principles of Mathematics de Russell ${ }^{53}$ ), Moore discute a doutrina 'idealista' segundo a qual ' $x$ é bom' significa ' $x$ é desejado'; doutrina que é a contrapartida, em ética, da tese epistemológica segundo a qual 'p é verdadeiro' significa ' $p$ é acreditado', a tese que 'constitui a parte mais essencial da 'revolução copernicana' de Kant na filosofia, e que torna imprestável a massa inteira de literatura moderna, a que essa revolução deu origem, que é chamada Epistemologia' (MOORE, 1903, p. 33) ${ }^{54}$.

Os idealistas, sustentava Moore, têm razão quando dizem que não poderíamos saber que é algo bom se não o desejássemos, assim como não poderíamos saber que algo existe se não o percebêssemos. Mas eles erram ao tomar essas condições 'subjetivas' de acesso às coisas por determinações objetivas das próprias coisas:

\footnotetext{
${ }^{53}$ Que, no Prefácio a esse livro, assinalava: 'Nas questões filosóficas fundamentais, minha posição, em todos os traços mais distintivos, é derivada do Sr. G. E. Moore.' (Russell, 1992, p. xviii).

${ }^{54}$ Do mesmo modo, no livro sobre Leibniz que publicara em 1900, Russell apresentava a teoria leibniziana segundo a qual relações são entia rationis como um pressuposto da concepção, 'que constitui boa parte da revolução copernicana de Kant, segundo a qual proposições podem tornarse verdadeiras por serem acreditadas'. (Bertrand Russell, A Critical Exposition of the Philosophy of Leibniz (London: Routledge, 1992), p. 14)
} 
Frequentemente se observa que eu não posso a momento algum distinguir o que é verdadeiro do que eu penso sê-lo: e isso é verdade. Mas embora eu não possa distinguir o que é verdadeiro do que eu penso sê-lo, sempre posso distinguir o que quero dizer ao dizer que algo é verdadeiro do que quero dizer ao dizer que eu penso que é. Pois eu compreendo o significado da suposição de que o que eu penso pode, mesmo assim, ser falso. (MOORE, 1903, p. 132)

Essa passagem contém, até onde eu sei, a primeira alusão, na obra publicada de Moore, à dificuldade que, anos mais tarde, Wittgenstein batizará 'Paradoxo de Moore' - e que, em 1948, será objeto dessa avaliação: 'Com seu paradoxo, Moore mexeu num ninho de vespas. E se as vespas não saíram voando como deviam, foi só porque estavam muito apáticas.' (WITTGENSTEIN, 1984, p. 76)

Em qualquer caso, certamente não é acidental que a apresentação do problema na secção x da assim-chamada 'Segunda Parte' das Investigações Filosóficas ecoe, no próprio léxico, a formulação de Principia Ethica:

O paradoxo de Moore pode ser expresso assim: a declaração (Äußerung) "Creio que as coisas estão assim" é usada de modo semelhante à asserção (Behauptung) "As coisas estão assim"; mas a suposição (Annahme) de que eu creio que as coisas estão assim não é usada como a suposição de que elas estão assim.

E o parágrafo imediatamente seguinte acena para a dificuldade com a qual, daí em diante, Wittgenstein tratará de acertar contas: 'Desse modo, parece que a asserção "Creio..." não é a asserção daquilo que é suposto na suposição "Creio..."!' (WITTGENSTEIN, 1989a, p. 513)

Mas essa formulação, como a de Moore em 1942, apenas arranha a superfície do problema, pois o que não se pode coerentemente asserir (embora trate-se de um estado de coisas logicamente possível), tampouco se pode pensar coerentemente - o que, de sua parte, Wittgenstein perce- 
beu em seguida. Eis como, em uma formulação lapidar do final dos anos 40, a dificuldade é apresentada: 'A linha " $\mathrm{x}$ está enganado" não tem ponto real para $\mathrm{x}=\mathrm{eu}$. Aqui a linha submerge na escuridão.' (WITTGENSTEIN, 1989b, v. I, $\S .427)^{55}$.

Comentando essa passagem, Thomas Baldwin observa que Wittgenstein está assinalando, como o fazia Moore em 1903 (mas, infelizmente, não mais em 1942), uma inescapável

fusão de nossa concepção sobre o mundo como ele é com nossa concepção do mundo como acreditamos que ele é. No caso das crenças dos outros, das próprias crenças passadas, e das crenças que hipoteticamente supomos ter, nenhuma fusão dessas acontece. Podemos supor que, se fôssemos capazes de adotar uma perspectiva inteiramente "de terceira pessoa" sobre nós mesmos, as conjunções mooreanas se tornariam admissíveis: 'E então seria também possível alguém dizer "Está chovendo e eu não acredito nisso" ou "Parece-me que meu ego acredita nisso, mas isso não é verdade". Teríamos de completar a imagem com um comportamento que indicasse que duas pessoas estavam falando pela minha boca.' (Investigações Filosóficas, p. 192). Mas a formulação de Wittgenstein mostra que não há saída para a impossibilidade de uma crença mooreana: mesmo se o eu se divide, o problema reaparece para a relação de cada ego com suas próprias crenças. (BALDWIN, 1990, p. 231) (B6 $^{56}$

A raiz da dificuldade foi apontada, com precisão cirúrgica, por Gareth Evans, a propósito de outra observação, caracteristicamente críptica, atribuída a Wittgenstein: 'Se um homem me diz, olhando para o céu, 'Penso que vai cho-

\footnotetext{
${ }^{55}$ Veja-se, a esse respeito, a iluminadora discussão de Thomas Baldwin (1990, p. 226-232).

${ }^{56}$ Em uma passagem dos Cahiers citada por Linville e Ring (1991, p. 300), Simone Weil observa: 'Um pintor não representa o lugar em que ele se encontra. Mas, olhando para a pintura, posso deduzir sua posição em relação às coisas representadas. Por outro lado, se ele representa-se a si mesmo na pintura, eu sei com certeza que o lugar onde ele aparece não é o lugar que ele ocupa.'
} 
ver, logo existo', eu não o compreendo'. ${ }^{57}$ Comentando essa observação, Evans escreve:

A contribuição é certamente epigramática; mas penso que Wittgenstein estava tentando solapar a tentação de adotar uma posição cartesiana, forçando-nos a examinar mais de perto a natureza de nosso conhecimento de nossos próprios atributos mentais, e, particularmente, forçando-nos a abandonar a ideia de que esse conhecimento sempre envolve um olhar voltado para dentro sobre estados e atividades a que só a própria pessoa tem acesso. O ponto crucial é o que eu assinalei em itálicos: ao fazer uma autoatribuição de crença, nossos olhos estão, por assim dizer, e às vezes literalmente, voltados para fora - para o mundo. Se alguém me pergunta 'Você acha que haverá uma terceira guerra mundial?' devo levar em conta, ao responder, exatamente os mesmos fenômenos que levaria em conta se devesse responder à pergunta 'Haverá uma terceira guerra mundial?'. Habilito-me a responder à pergunta se creio que $p$ empregando qualquer procedimento de que disponha para responder à pergunta se $p$. (EVANS, 1982, p. 225)

É porque a autoatribuição de um juízo é, assim, parasitária, da formação do juízo - porque, no jargão de Moran, a 'descoberta' acerca de si é parasitária da 'resolução' ${ }^{58}$ - que 'Creio que p' pode ser usado como a 'afirmação hesitante' de $p$, sem que por isso as conjunções anômalas de Moore sejam contradições: dizê-lo é chover no molhado, mas, afinal de contas (e 'infelizmente', como diria Russell), o erro (creio que $p$, mas ' $p$ ' é falso) e a ignorância ('p' é verdadeiro, mas não creio que p) são, como insistia justamente Moore, 'perfeitamente possíveis'.

O paradoxo consiste em que, para todo sujeito $S$, haja pelo menos uma proposição possivelmente verdadeira acerca de S que S não pode coerentemente tomar por verdadeira;

\footnotetext{
${ }^{57}$ Coope, Geach, Potts \& White, 1971, p. 21 (itálicos acrescentados por Evans).

${ }^{58}$ Cf. Moran, 2001, pp. 64-99.
} 
o que, todavia, não o impede de supor sua verdade - desde que, nas palavras de Moore, 'compreenda a suposição de que o que crê ser verdadeiro possa, mesmo assim, ser falso'.

Posso supor que erro ou desconheço a verdade - de onde o caráter não-paradoxal, em paridade com suas contrapartidas na segunda ou terceira pessoa, ou no tempo pretérito, da contrapartida no modo subjuntivo das conjunções de Moore. Mas, se o problema não é, como venho insistindo, linguístico (se o que está em jogo, mais do que o que pode ser dito, é o que pode ser pensado), por que eu não poderia expressar essa suposição, sem evocar a sombra de um paradoxo, também na primeira pessoa do tempo presente do modo indicativo?

A resposta (e com isso chegamos ao que mais interessou Wittgenstein no 'ninho de vespas' em que Moore havia mexido) é: posso fazê-lo, sim! Para dar apenas o exemplo mais pertinente à presente discussão, que outra coisa fazemos ao ler, por exemplo, a Primeira Meditação cartesiana? ${ }^{59}$

Mas, para ler com compreensão um texto como a Primeira Meditação, é preciso não perder de vista a distinção, para a qual Descartes não se cansou de chamar atenção, entre 'investigação da verdade' e 'uso da vida': em outras palavras, é preciso já estar pensando nesse regime de dissociação que Hume dramatizou no final do Livro I do Treatise, e Burnyeat chamou 'insulamento'. Do contrário, incorreremos no erro do Padre Bourdin, criticado nas Respostas às Sétimas Objeções. Descartes afirmara, no final da Primeira Meditação,

\footnotetext{
${ }^{59}$ A ideia de que o 'indicativo' cartesiano é "gramática de superfície" de um discurso logicamente subjuntivo (contrafactual), e a sugestão de ler a Primeira Meditação como uma vasta conjunção mooreana "normalizada" ('Suponhamos que eu creia que p, mas não-p') encontram-se em Kent Linville (1979).
} 
que não era 'por inconsideração ou leviandade, mas por razões muito sólidas e meditadas (propter validas et meditatas rationes)' que ele se dispunha a rejeitar todas as suas opiniões precedentes, não lhes dando mais crédito do que daria a coisas que lhe parecessem 'manifestamente falsas' (AT VI, 21). A seriedade dessa alegação foi impugnada pelo Padre Bourdin, esse Moore avant la lettre: como posso conceber que sólidas e meditadas razões me façam duvidar de que, por exemplo, 'existem uma terra, um céu, cores; de que tens uma cabeça, olhos, corpo e mente [...] que dois mais três são cinco, que o todo é maior que sua parte, e coisas semelhantes?' (AT VI, 455). A hipótese do Gênio Maligno, que esse leitor atento reconhece minar os fundamentos da certeza que emprestamos a essas crenças, deve por acaso ser admitida como uma razão séria e meditada? Para o Padre Bourdin, se aqui está uma mão humana, e aqui está outra, tollitur quaestio ${ }^{60}$.

Em sua resposta, Descartes atribui a objeção a um completo mal-entendido. O Padre Bourdin confunde o que pertence à 'investigação da verdade' e o que é próprio do 'uso da vida' - ele não reconhece a autonomia do 'contexto', como diria um epistemólogo de nossos dias, da investigação filosófica. E é assim que

esse homem laborioso e sincero oferece como exemplos coisas das quais eu disse que se poderia duvidar por boas e sérias razões, a saber, se existe uma terra, se eu tenho um corpo, e coisas semelhantes, a fim de que os leitores que não tiverem familiaridade com essa dúvida metafísica, relacionando-a com o uso e a conduta da vida, me tomem por alguém que perdeu o juízo. (AT VII, 460)

\footnotetext{
${ }^{60}$ Para Wittgenstein, em troca: 'Se você sabe que aqui está uma mão, nós lhe concederemos todo o resto.' (Über Gewissheit, § 1). O problema está, justamente, no antecedente desse condicional.
} 
Em resumo: posso dizer de um terceiro que ele crê que $p$, mas $p$ é falso; posso dizer de mim mesmo que tive crenças falsas; por fim, posso supor, de mim mesmo, que creio (presentemente) que $p$, mas p é falso. É essa última possibilidade que, sobretudo, ocupou Wittgenstein em sua discussão do Paradoxo de Moore: a possibilidade de submeter a um escrutínio "impessoal" as próprias atitudes proposicionais, pensando acerca de si mesmo como se pensaria acerca de outrem - da "perspectiva da terceira pessoa".

A questão é: como podemos fazê-lo? Quando tento responder a essa pergunta, é como se eu tentasse imaginar uma situação em que diria de alguém que crê falsamente e esse alguém, de quem eu falaria como de qualquer outro, fosse eu. Quando imagino essa situação, é como se estivesse a observar, sem delas tomar parte, as atividades de outras pessoas, e descrevesse o que estavam fazendo - e então resultasse que, dentre essas pessoas, eu pudesse apontar para uma determinada, e, como quem aponta para uma velha foto de formatura, dizer: '... e aquele ali sou eu'.

Se agora prossigo com essa fantasia, e imagino que eu tomasse conhecimento das opiniões dessas pessoas (por exemplo, escutando o que dizem), posso muito bem conceber que dissesse, ao relatar o que descobri: 'A julgar pelo que estou dizendo, creio que $p$; mas isso é falso.' (WITTGENSTEIN, 1989a, II, x, p. 516).

É de minha vida que eu estaria falando - de minhas opiniões, das coisas que penso e digo - se é certo que 'aquele ali sou eu'. Mas, na situação imaginada, eu falaria de minha vida como se a contemplasse, por assim dizer, 'de fora', como o espectador de um filme.

O que estou fazendo ao imaginar uma situação como a que descrevi é um exercício de ficção: a descrição contrafac- 
tual de uma situação (pelo menos logicamente) possível. Essa ficção fornece um ambiente (no jargão de Wittgenstein, um "jogo de linguagem") que normaliza a conjunção de Moore, cancelando sua aparência paradoxal. Mas, antes que me seja objetado que isso é obtido ao preço de um paradoxo ainda maior (que eu me tornasse espectador de minha própria vida, como se a contemplasse 'de fora'), convido o leitor a refletir sobre o que significa dizer que isso é um exercício de ficção ${ }^{61}$.

A invenção, no final do século XIX, das 'personalidades múltiplas', ${ }^{62}$ inspirou a Stevensou a narrativa fantástica The Strange Case of Dr. Jekyll and Mr. Hyde, evocada por Wittgenstein no Blue Book para ilustrar uma situação em que nossos critérios usuais de identidade pessoal entrariam em colapso (WITTGENSTEIN, 1969, p. 62). Mas uma situação assemelhada, envolvendo a mesma fantasia de "dupla personalidade", fornece, nas Observações sobre a Filosofia da Psicologia, um cenário em que a conjunção de Moore seria asserida sem absurdo:

"Supondo que está chovendo e eu não acredito nisso" - quando eu afirmo o que é suposto nessa suposição, - então, por assim dizer, minha personalidade se divide em duas.

"Então minha personalidade se divide em duas" significa: então eu não jogo mais o jogo de linguagem costumeiro, mas um jogo diferente. (WITTGENSTEIN, 1989b, I, § 820).

Do mesmo modo, a seção x da assim-chamada 'Segunda Parte' das Investigações Filosóficas convida-nos a imaginar

\footnotetext{
${ }^{61}$ Eis, na prosa do mais filosófico dos escritores do século XX, o insulamento consumado: 'Ele fala de si mesmo como de um outro. Ele diz, falando de si mesmo, Ele fala de si mesmo como de um outro.' (BECKETT, 1996, p. 18).

${ }^{62}$ Cf. Hacking, 1989; 1996.
} 
uma situação em que identificaríamos nossas crenças pelo que dizemos, como fazemos com as crenças dos outros. Essa seria uma situação em que teria sentido dizer: 'A julgar pelo que estou dizendo, creio nisso' ${ }^{63}$. Foi uma situação como essa que descrevi quando me imaginei observando, como um espectador (como se assistisse ao 'filme de minha vida') as palavras e ações de um grupo de pessoas, uma das quais era eu.

$\mathrm{E}$, se isso parecia, como sugeri, trocar um paradoxo por outro, era apenas porque, tal como a descrevi, a situação envolvia minha "duplicação", a introdução de uma réplica ou Doppelgänger - de tal forma que uma de suas extensões possíveis seria a inversão simétrica do ponto de vista do narrador: em uma continuação possível da história, o personagem que apontei dizendo (como quem aponta para uma foto) que era eu, passaria a falar na primeira pessoa - e, de sua perspectiva, talvez olhasse para (mim?) dizendo: 'E aquele lá sou eu. ${ }^{64}$

Essa indicações são muito sumárias, mas talvez lancem alguma luz sobre a insistência quase obsessiva com que Wittgenstein se dedicou a imaginar situações contrafactuais ('jogos de linguagem') que normalizariam as conjunções anômalas de Moore, ao preço de evocar, conforme o caso, a hipocrisia, (WITTGENSTEIN, 1989b, I, § 486) a fraqueza da vontade, (Ibid., § 496) a megalomania, (Ibid., § 816) a 'cisão’ esquizofrênica, (Ibid., § 820) a obsessão (Ibid., § 821) ou

\footnotetext{
63 'Se eu escutasse as palavras que minha boca profere, poderia dizer: "Eu pareço acreditar". (Wittgenstein, 1989a, p. 516).

${ }^{64}$ Uma exploração, de extraordinário impacto dramático, dessa possibilidade constitui a trama do conto de Julio Cortázar, 'Lejana', em Bestiario (1982, p. 37-49). Duas variantes dessa situação foram exploradas, em direções diferentes, por Cortázar nos contos 'Axolotl', em Final del Juego (1968, p. 161-169), e 'La Isla a Mediodía', em Todos los Fuegos el Fuego (1970, p. 117-127).
} 
o ciúme (WITTGENSTEIN, 1989b, II, § 417): em todos os casos, a dissociação de um sujeito por cuja boca como que 'falariam duas pessoas'.

'De um modo ou de outro', escrevia Burnyeat sobre o epistemólogo entregue à 'profunda e intensa reflexão' de que falou Hume, 'ele insula seus juízos ordinários de primeira ordem dos efeitos de sua filosofia'. De um modo ou de outro, anota Wittgenstein, 'sua personalidade se divide em duas'.

Em sua 'Defesa do Senso Comum', Moore pretendera lançar um ataque radical a essa dissociação:

O que é estranho é que filósofos tenham sido capazes de sustentar sinceramente, como parte de seu credo filosófico, proposições inconsistentes com o que eles mesmos sabiam ser verdadeiro; e, no entanto, até onde percebo, isso de fato aconteceu com frequência. (MOORE, 1959, p. 40)

Como Peirce (1965, p.157) na época de Stevenson, ou Reid na de Hume, Moore queria convidar os filósofos a não fingirem duvidar daquilo de que não duvidavam 'em seus corações'. Mas, como observa Wittgenstein a propósito de um desses célebres exemplos mooreanos de coisas das quais (nas palavras de Descartes), 'ninguém em seu são juízo jamais duvidou', a tentativa de Moore desconhecia ainda a distância que separa, por um lado, a espécie de situação em que alguma das proposições citadas por Moore podia ser empregada com sentido e, por outro, o que pensamos estar fazendo ao apresentar uma prova filosófica - por exemplo, do 'mundo exterior'. ${ }^{65}$

\footnotetext{
65 'De uma proposição prática nenhuma proposição filosófica pode seguir-se. A proposição de Moore era uma proposição prática deixada indeterminada.' (WITTGENSTEIN, 1949-1952, p. 44).
} 
Em suma, o que, ao sucumbir à tentação de 'refutar o cético', Moore não enxergava era a parte de encenação - de finta, de pose, de faz-de-conta - que subsistia em seu próprio empreendimento: 'Considera: - "Não é verdade que eu creio sempre falsamente. Por exemplo, agora está chovendo, e eu creio nisso." Poderíamos dizer dele: Ele fala como duas pessoas'. (WITTGENSTEIN, 1989b, I, § 787)

Esse breve apanhado da complexa e fascinante discussão que Wittgenstein dedicou ao Paradoxo de Moore será suficiente, espero, para elucidar esta enigmática passagem do MS 169 (circa 1949) em que aparece, justaposta à imagem de uma representação teatral, a do vespeiro que Moore havia descoberto:

O melhor exemplo de uma expressão com um significado bem determinado é uma passagem numa peça de teatro.

-. Então pressupomos um monte de coisas. Por exemplo, que eles escutam suas próprias vozes, e, também, que às vezes seus gestos são acompanhados por sentimentos, e tudo o mais que pertence à vida humana.

Mexer num ninho de vespas. Moore. (WITTGENSTEIN, 1989b, v. II, p. 8)

E, assim, chegamos à conclusão - forçosamente provisória, nem por isso 'uma asserção hesitante' - deste escrito. Se as aparentes violações do Princípio de Fechamento Epistêmico são, como penso haver mostrado, artefatos das condições "dramatúrgicas" muito peculiares em que é instaurado e conduzido o inquérito epistemológico sobre a confiabilidade das fontes do conhecimento (percepção, memória, testemunho, inferência), e, em particular, do recurso à impropriamente denominada "dúvida" cética na instrução desse inquérito, então o impasse que chamei a 'Enrascada 
de Hume' deve ser reconhecido, também, como o desfecho de algo como uma 'dialética natural da razão', no sentido que Kant deu a essa expressão. Pois, no curso do inquérito (no 'contexto', mas eu não preciso dessa palavra, da reflexão epistemológica) a possibilidade de um juízo estar insuficientemente justificado pareceria exigir, como um imperativo de responsabilidade epistêmica (da reflexividade como princípio regulativo ou Norma da Razão), que, de fato, não o empregássemos como premissa na formação de novos juízOS.

Mas, nesse caso, o abandono do Princípio de Reflexividade não apenas não impõe o do Princípio de Fechamento Epistêmico: pode mesmo ser, algo inesperadamente, sua melhor defesa.

Abstract: The paper discusses the relations between two putative epistemic principles, Reflexivity and Closure, with a view to assess whether the repudiation of the former, usually required by externalistic accounts of knowledge, necessitates the repudiation, as well, of the latter. A negative reply to that question is offered, which prompts the hypothesis that alleged counterexamples to Closure are artifacts of the rather peculiar conditions on which, in the course of a particular kind of epistemological inquiry, are introduced assumptions such as are characteristic of the methodological use of so-called skeptical "doubts".

Keywords: Skepticism, Epistemic Principles, Closure, Rationality, Reflexivity, Moore's Paradox.

\section{REFERÊNCIAS}

ADAMS, Fred \& CLARKE, Murray. Toward saving Nozick from Kripke. In: LÖFFLER, W.; WEINGARTNER, P. (Eds.). Knowledge and belief. Proceedings of the $26^{\text {th }}$ International Wittgenstein Symposium, 03-09 August, 2003. Kirchberg: Hölder-Pichler-Tempsky, 2004. pp. 18-20. 
ANSCOMBE, Elizabeth. Subjunctive conditionals. In: Metaphysics and the philosophy of mind. Minneapolis: University of Minnesota Press, 1981. p. 196-207.

ARMSTRONG, David M. Belief, truth and knowledge. Cambridge: Cambridge University Press, 1973. p. 162-183.

AUSTIN, J. L. Other minds (1942). In: Philosophical papers. $3^{\text {rd }} \mathrm{ed}$. Oxford: Oxford University Press, 1979.

BALDWIN, Thomas. G. E. Moore. London \& New York: Routledge, 1990.

BECKETT, Samuel. Company. In: Nohow On (Company, IIl Seen IIl Said, Worstward Ho), three novels by Samuel Beckett. New York: Grove Press, 1996.

BERNECKER, Sven \& DRETSKE, Fred. Introduction. Knowledge: Readings in contemporary epistemology. Oxford: Oxford University Press, 2000.

BOGDAN, Radu J. Cognition and epistemic closure. American Philosohical Quarterly, n. 22, p. 55-63, 1985.

BORGES, Jorge Luís. Kafka y sus precursores. In: Otras inquisiciones. Madrid: Alianza Editorial, 1976.

BRANDON, Robert. Insights and blindspots of reliabilism. In: Articulating reasons: an introduction to inferentialism. Cambridge, MA: Harvard University Press, 2000. p. $97-$ 122.

- Knowledge and the social articulation of the space of reasons. Philosophy and Phenomenological Research, n. 55, p. 895-908, 1995. 
BRUECKNER, Anthony. Klein on closure and skepticism. Philosophical Studies, n. 98, p. 139-151, 2000.

. Skepticism and epistemic closure. Philosophical Topics, n. 13, p. 89-117. 1985.

BURNYEAT, Myles. The Theaetetus of Plato. Indianapolis: Hackett Publishing Company, 1990.

$\&$ BARNES, Jonathan. Socrates and the jury: Paradoxes in Plato's distinction between knowledge and true belief. Aristotelian Society Supplementary, v. 54, p. 173206, 1980.

, BARNES, Jonathan \& FREDE, Michael. The original sceptics: a controversy. Indianapolis/Cambridge: Hackett Publishing Company, 1997.

CAVELL, Stanley. The claim of reason: Wittgenstein, skepticism, morality, and tragedy. Oxford: Oxford University Press, 1979.

CHANTRAINNE, Pierre. Dictionnaire etimologique $d u$ Grecq Ancien. Tomo I. Paris: Klincksieck, 1990.

CHISHOLM, Roderick. The contrary-to-fact conditional. Mind, n. 55, p. 289-307, 1946.

CLARKE, Thompson. The legacy of skepticism. Journal of Philosophy, n. 69, p. 754-769, 1972.

COOPE, Christopher; GEACH, Peter; POTTS, Timothy; WHITE, Roger (Eds.). A Wittgenstein workbook. Oxford: Blackwell, 1971.

CORTÁZAR, Julio. Final del juego. Buenos Aires: Edito- 
rial Sudamericana, 1968.

. Bestiario. Madrid: Ediciones Alfaguara, 1982.

- Todos los fuegos el fuego. Buenos Aires: Editorial Sudamericana, 1970.

DAVIDSON, Donald. The second person. In: Subjective, intersubjective, objective. Oxford: Oxford University Press, 2001. p. 107-121.

DAY, Jane (Ed.). Plato's Meno in focus. London \& New York: Routledge, 1994.

DE ALMEIDA, Claudio. Closure, defeasibility and conclusive reasons. Acta Analytica, n. 22, p. 301-319, 2007.

. Moorean absurdity: an epistemological analysis. In: GREEN, Mitchell; WILLIAMS, John N. (Eds.). Moore's Paradox: New essays on belief, rationality and the first person. Oxford: Clarendon Press, 2007. p. 53-75.

. Racionalidade Epistêmica e o Paradoxo de Moore. Veritas, n. 54, p. 48-73, 2009.

. What Moore's paradox is about. Philosophy and Phenomenological Research, n. 52, p. 33-58, 2001.

DESCARTES, René. Euvres de Descartes publiées par Charles Adam et Paul Tannéry. Paris: Vrin/CNRS, 19761982.

DRETSKE, Fred. Conclusive reasons. Australasian Journal of Philosophy, n. 49, p. 1-22, 1971.

. Epistemic Operators. Journal of Philosophy, n. 67, p. 1007-1023, 1970, reimpresso em Perception, knowledge, 
and belief: selected essays. Cambridge: Cambridge University Press, 2000. p. 30-47.

- Two conceptions of knowledge: Rational vs. reliable belief. In: Perception, knowledge, and belief: selected essays. Cambridge: Cambridge University Press, 2000. p. $80-93$.

ENGEL Jr., Mylan. Is epistemic luck compatible with knowledge? Southern Journal of Philosophy, n. 30, p. 5975, 1992.

EVANS, Gareth. The varieties of reference. Ed. John McDowell. Oxford: Clarendon Press, 1982.

FARIA, Paulo. Discriminação e conhecimento de si. In: PINHEIRO, Ulysses; RUFFINO, Marco; SMITH, Plínio Junqueira (Eds.). Ontologia, conhecimento e linguagem: um encontro de filósofos latino-americanos. Rio de Janeiro: FAPERJ/Mauad, 2001. p. 113-128.

- Le guêpier de Moore. In: LAUGIER, Sandra (Ed.). Wittgenstein: Métaphysique et jeux de langage. Paris: Presses Universitaires de France, 2001. p. 129-152.

. A preservação da verdade. $O$ que nos faz pensar, Rio de Janeiro, PUC, n. 20, p. 101-126, 2006.

. Unsafe reasoning: a survey. Dois Pontos, UFPR, n. 6, p. 185-220, 2009.

- Anti-individualismo e autoconhecimento: uma exposição elementar. In: SILVA FILHO, Waldomiro (Ed.). Mente, linguagem e mundo. São Paulo: Alameda Editorial, 2010. p. 25-35. 
FELDMAN, Richard. In defence of closure. The Philosophical Quarterly, n. 45, p. 487-499, 1995.

GETTIER, Edmund. Is justified true belief knowledge? Analysis 23, p. 121-123, 1963.

GOLDFARB, Warren. Wittgenstein and the fixity of meaning. In: TAIT, William W. Early analytic Philosophy. Chicago: University of Chicago Press, 1997. p. 75-89.

GOLDMAN, Alvin I. A causal theory of knowing. The journal of Philosophy, n. 64, p. 357-372, 1967.

. Discrimination and perceptual knowledge. The Journal of Philosophy, n. 73, p. 771-791, 1976.

GOODMAN, Nelson. Fact, fiction and forecast. $4^{\text {th }}$ ed. Cambridge: Harvard University Press, 1983.

. The problem of counterfactual conditionals. The $\overline{\text { Journal }}$ of Philosophy, n. 44, p. 113-128, 1947.

HACKING, Ian. Rewriting the Soul: Multiple personality and the sciences of memory. Princeton: Princeton University Press, 1996.

The invention of split personalities. In: DONAGAN, A.; PEROVICH JR., A. N.; VEDIN, N. V. Human nature and natural knowledge. Dordrecht: Reidel, 1989. p. 63-85.

HEIDEGGER, Martin. Sein und Zeit. Siebzehnte auflage. Tübingen: Max Niemeyer Verlag, 1993.

HELLER, Mark. Relevant alternatives and closure. Australasian Journal of Philosophy, n. 77, p. 196-208, 1999. 
HILPINEN, Risto. KK-thesis. In: A companion to Epistemology. Ed. Jonathan Dancy \& Ernest Sosa. Oxford: Blackwell, 1992.

HINTIKKA, Jaakko. Knowledge and belief: an introduction to the logic of the two notions. Ithaca, NY: Cornell University Press, 1962.

HUME, David. A treatise of human nature. Ed. L. A. Selby-Bigge. Oxford: Clarendon Press, 1978.

- An enquiry concerning human understanding. Ed. Peter Millican. Oxford: Oxford University Press, 2007. JACKSON, Frank. Conditionals. Oxford: Blackwell, 1987.

(Ed.). Conditionals. Oxford: Oxford University Press, 1991.

KLEIN, Peter. Skepticism and closure: Why the evil genius argument fails. Philosophical Topics, n. 23, p. 215-38, 1996.

LEWIS, David K. Counterfactuals. Oxford: Blackwell, 1973.

. Elusive knowledge. The Australasian Journal of Philosophy, n. 74, p. 549-567, 1996, reimpresso em Papers in Metaphysics and Epistemology. Cambridge: Cambridge University Press, 1999. p. 418-445.

LINVILLE, Kent. Wittgenstein on "Moore's paradox". In: LUCKHARDT, C. G. Wittgenstein: Sources and perspectives. Hassox, Sussex: The Harvester Press, 1979. p. 286302. 
LINVILLE, Kent; RING, Merril. Moore's paradox revisited. Synthese, n. 87, p. 295-309, 1991.

LUPER-FOY, Steven (Ed.). The possibility of knowledge: Nozick and his critics. Totowa, NJ: Rowman \& Littlefield, 1987.

MCCULLOUCH, Gregory. Using Sartre: an analytical introduction to early sartrean themes. London: Routledge, 1994. p. 106-111.

MCDOWELL, John. Identity mistakes: Plato and the Logical Atomists. In: Meaning, knowledge, and reality. Cambridge, MA: Harvard University Press, 1998. p. 157-170.

1973.

- Plato: Theaetetus. Oxford: Clarendon Press,

MCGINN, Colin. The concept of knowledge. Midwest Studies in Philosophy, n. IX, p. 529-554, 1984.

MORAN, Richard. Authority and estrangement: an essay of self-knowledge. Princeton \& Oxford: Princeton University Press, 2001.

MOORE, G. E. A defence of common sense. In: Philosophical papers. London: George Allen \& Unwin, 1959. p. 32-59.

. A reply to my critics. In: SCHILPP, Paul Arthur (Ed.). The philosophy of G. E. Moore. LaSalle: Illinois: Open Court, 1942. p. 535-687.

. Principia Ethica. Cambridge: Cambridge University Press, 1903. 
NOZICK, Robert. Philosophical Explanations. Cambridge, MA: Harvard University Press, 1981.

PEIRCE, Charles Sanders. Consequences of commonsensism. In: HARTSHORNE, Charles; WEISS, P. (Eds.). Collected papers of Charles Sandres Peirce. v. V - Pragmatism and Pragmaticism. Cambridge, Massachusetts: Harvard University Press, 1965. p. 361-362 [§ 5.514]

- Some consequences of four incapacities. In: HARTSHORNE, Charles; WEISS, P. (Eds.). Collected papers of Charles Sandres Peirce. v. V - Pragmatism and Pragmaticism. Cambridge, Massachusetts: Harvard University Press, 1965. p. 156-189.

PEREIRA, Roberto Horácio de Sá. Ceticismo e contrafactuais. In: PINHEIRO, Ulysses; RUFFINO, Marco; SMITH, Plínio Junqueira (Eds.). Ontologia, conhecimento e linguagem. Rio: Mauad/FAPERJ, 2001. p. 205-221.

PIERI, Stefania Nonvel. Le dialogue platonicien comme forme de pensée ironique. In: COSSUTA, Frédéric; NARCY, Michel (Eds). La forme dialogue chez Platon: évolution et réception. Grenoble: Editions Jérôme Millon, 2001. p. 21-48

PRITCHARD, Duncan. Closure and context. Australasian Journal of Philosophy, n. 78, p. 275-280, 2000.

2005.

. Epistemic luck. Oxford: Oxford University Press,

RAMSEY, Frank P. Last papers (1929): Knowledge. In: BRAITHWAITE, R. R. (Ed.). The foundations of Mathematics and other logical essays. Totowa, NJ: Littlefield, 
1965. p. 258-259.

RYLE, Gilbert. Logical atomism in Plato's Theatetus. Phronesis, n. 35, p. 21-46, 1990.

RUSSELL, Bertrand. A critical exposition of the Philosophy of Leibniz. London: Routledge, 1992.

. My Philosophical Development. London: Routledge, 1959.

SANFORD, David. If $P$ then $Q$. London: Routledge, 1989.

SORENSEN, Roy A. Dogmatism, junk knowledge, and conditionals. The Philosophical Quarterly, n. 38, p. 433454, 1988.

SOSA, Ernest. Apt belief and reflective knowledge. v. I. Oxford: Oxford University Press, 2007.

- Apt belief and reflective knowledge. v. II. Oxford: Oxford University Press, 2009.

STEUP, Matthias; SOSA, Ernest (Eds.). Contemporary debates in Epistemology. Oxford: Blackwell, 2005.

STINE, Gail C. Dretske on knowing the logical consequences. The Journal of Philosophy, n. 68, p. 296-299, 1971.

- Skepticism, relevant alternatives, and deductive closure. Philosophical Studies, n. 29, p. 249-261, 1976.

STROUD, Barry. Scepticism, externalism, and the goal of Epistemology. In: Understanding human knowledge: Philosophical Essays. Oxford: Oxford University Press, 2000. 
p. 139-154.

. The significance of Philosophical scepticism. Oxford: Oxford University Press, 1984.

THALBERG, Irving. Is justification transmissible through deduction? Philosophical Studies, n. 25, p. 347-356, 1976.

VLASTOS, Gregory. Anamnesis in the Meno. Dialogue, n. 4, p. 143-67, 1965.

VOGEL, Jonathan. Are there counterexamples to the closure principle? In: ROTH, M.; Roth \& G. Ross, G. (Eds.). Doubting. Dordrecht: Kluwer, 1990. p. 13-27.

WALTON, Kendall. Fearing fictions. The Journal of Philosophy, n. 75, p. 5-27, 1978.

- Mimesis as make-believe: on the foundations of the representational arts. Cambridge, Mass.: Harvard University Press, 1990.

. Pictures and make-believe. The Philosophical Review, n. 82, p. 283-319, 1973.

WILLIAMS, Michael. Unnatural doubts: Epistemological realism and the basis of scepticism. Princeton: Princeton University Press, 1996.

WITTGENSTEIN, L. Bemerkungen über die Philosophie der Psychologie. Werkausgabe Band 7. Frankfurt: Suhrkamp. 1989b.

Blackwell, 1969.

- The blue and the brown books. Oxford: - Letze schriften über die Philosophie der 
Psycologie. Werkausgabe Band 7. Frankfurt: Suhrkamp, 1989c.

- Philosophische Untersuchungen. Werkausgabe Band 1. Frankfurt: Suhrkamp, 1989a.

. Culture and value / Vermischte Bemerkungen. Trad. de Peter Winch. Chicago: The University of Chicago Press, 1984.

YOURGRAU, Palle. Knowledge and relevant alternatives. Synthese, n. 55, p. 175-190, 1983. 